\title{
Functional Consequences of Mutations in the Myosin Regulatory Light Chain Associated with Hypertrophic Cardiomyopathy
}

\author{
Priya Muthu, Wenrui Huang, \\ Katarzyna Kazmierczak and Danuta Szczesna-Cordary \\ University of Miami Miller School of Medicine, Miami, FL,
}

USA

\section{Introduction}

Familial hypertrophic cardiomyopathy (FHC) is an autosomal dominant disease characterized by left ventricular wall thickening, myofilament disarray and abnormal echocardiography findings. Molecular genetic studies have defined FHC as a disease of the sarcomere caused by mutations in all major sarcomeric proteins, such as $\beta$-myosin heavy chain $(44 \%)$, myosin binding protein $C(35 \%)$, regulatory light chain $(2 \%)$, essential light chain $(1.6 \%)$, a-tropomyosin $(2.5 \%)$, troponin $\mathrm{T}(7 \%)$, troponin I $(5 \%)$, troponin C $(\sim 1 \%)$, aactin $(1 \%)$, and titin (<1\%) (Alcalai et al., 2008).

Although mutations in the regulatory light chain (RLC) of myosin are rare, they are of great significance given the importance of RLC for muscle contraction and heart function. The RLC plays an essential structural and functional role by supporting the architecture of the myosin neck region and fine-tuning the kinetics of the actin-myosin interaction (Morano, 1999; Szczesna, 2003). As shown in Fig. 1, the RLC wraps around the a-helical neck region of the myosin head by binding to a 35 amino acid IQ motif in the myosin heavy chain (MHC) (Rayment et al., 1993). This domain of MHC is anticipated to act as a lever arm, amplifying small conformational changes that originate at the catalytic site into large movements thus allowing myosin to generate motion and force (Geeves \& Holmes, 2005; Lowey et al., 1993). Furthermore, this neck region has been proposed to serve as the compliant element of the myosin cross-bridge with the RLC contributing to the stiffness of the lever arm (Howard \& Spudich, 1996; Pant et al., 2009). Two functionally important domains of the RLC molecule include its $\mathrm{Ca}^{2+}-\mathrm{Mg}^{2+}$ binding site, comprised of the Nterminal helix-loop-helix EF-hand $\mathrm{Ca}^{2+}$ binding motif, and a highly conserved N-terminal phosphorylatable serine constituting a myosin light chain kinase (MLCK)-dependent phosphorylation site.

The N-terminal divalent cation-binding site of the RLC is thought to be occupied by $\mathrm{Mg}^{2+}$ when muscles are in the relaxed state and may become partially saturated with $\mathrm{Ca}^{2+}$, depending on the length of the $\left[\mathrm{Ca}^{2+}\right]$ transient (Robertson et al., 1981). The MLCK phosphorylation site of RLC is also of great structural and functional importance. Phosphorylation of this site in smooth muscle activates contraction (Hartshorne \& Mrwa, 1982; Small \& Sobieszek, 1977; Sobieszek, 1977). In skeletal and cardiac muscle, $\mathrm{Ca}^{2+}$ 
calmodulin (CaM) activated MLCK phosphorylation of RLC modulates contraction by increasing the $\mathrm{Ca}^{2+}$ sensitivity and the level of force and also by modulating the kinetics of force generating myosin cross-bridges (for review see (Kamm \& Stull, 2011)). Of particular importance, the phosphorylation of RLC has been shown to regulate the function of myosin in the heart (Morano, 1999; Szczesna, 2003). Attenuation of RLC phosphorylation was demonstrated to lead to ventricular myocyte hypertrophy with histological evidence of necrosis and fibrosis (Ding et al., 2010). Recent results from Szczesna-Cordary's lab shown that RLC phosphorylation plays an essential role not only in the physiological performance of the heart, but also helps to maintain normal cardiac function in the diseased myocardium (Muthu et al., 2011). At the level of protein, the phosphorylation of RLC at Ser-15 was shown to alter the secondary structure (a-helical content) and $\mathrm{Ca}^{2+}$ binding affinity of the human ventricular RLC protein (Szczesna et al., 2001). At the level of myofilaments, RLC phosphorylation was demonstrated to result in a significantly decreased distance between the myosin heads and actin filaments bringing them closer to each other (Colson et al., 2010)

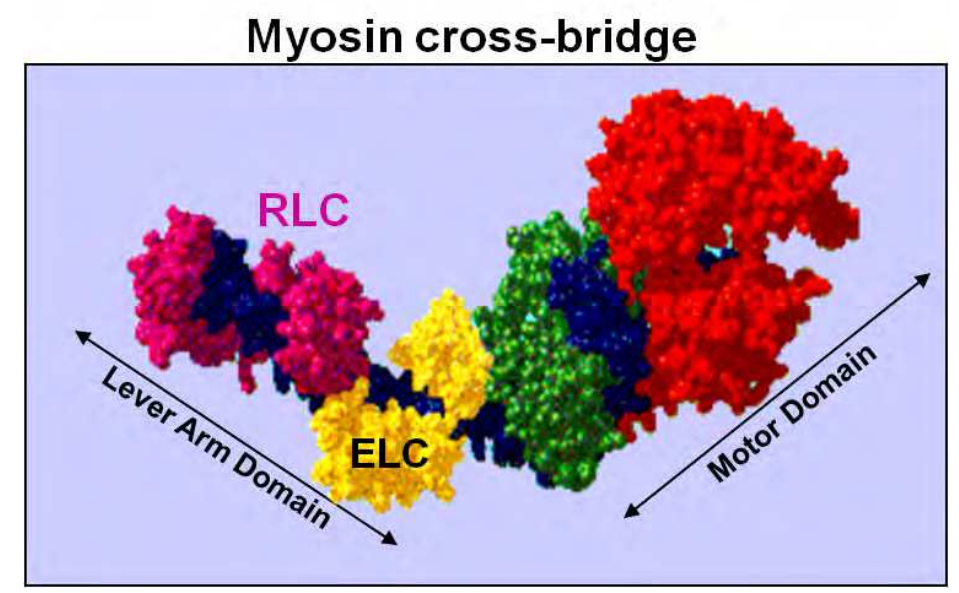

Fig. 1. Schematic representation of the myosin head (cross-bridge) containing regulatory (RLC, labeled in magenta) and essential (ELC, labeled in yellow) light chains. Indicated are 1) motor domain, and 2) lever arm (Rayment et al., 1993).

\subsection{FHC-linked mutations in the regulatory light chain (RLC)}

To date, eight single point mutations and two intron alternative splicing mutations in the MYL2 gene encoding for the human ventricular RLC (Swiss-Prot: P10916) have been identified to cause FHC (Fig. 2). They are A13T (alanine to threonine), F18L (phenylalanine to leucine), E22K (glutamic acid to lysine), N47K (asparagine to lysine), R58Q (arginine to glutamine), P95A (proline to alanine), K104E (lysine to glutamic acid), D166V (aspartic acid to valine), IVS5-2 (a A>G transversion in intron 5 that leads to a premature termination codon), and IVS6-1 (a G>C transversion in the acceptor splice site of intron 6).

The A13T mutation arises from a replacement of alanine, an uncharged and nonpolar amino acid by threonine, an uncharged but polar amino acid. The mutation was first discovered in an American patient (Poetter et al., 1996) and was later found in a Danish proband diagnosed 
with hypertrophic cardiomyopathy (HCM). Two of his family members were found to be heterozygous for the mutation (Andersen et al., 2001). The proband, 42 years old, suffered from exercise-induced dyspnoea and had pronounced septal hypertrophy, diastolic filling abnormities but no significantly increased left ventricular outflow tract. One of the family members, the mother of the proband, was diagnosed with HCM late in life and died at the age of 72; while the other, 10 years old, showed no sign of HCM. In 2005, another proband carrying the A13T mutation was also identified in a Danish population (Hougs et al., 2005). Overall, this mutation is associated with a rare HCM phenotype characterized by mid left ventricular obstruction, enlarged papillary muscles and profound septal hypertrophy.

12q23-q24.3 MYL2

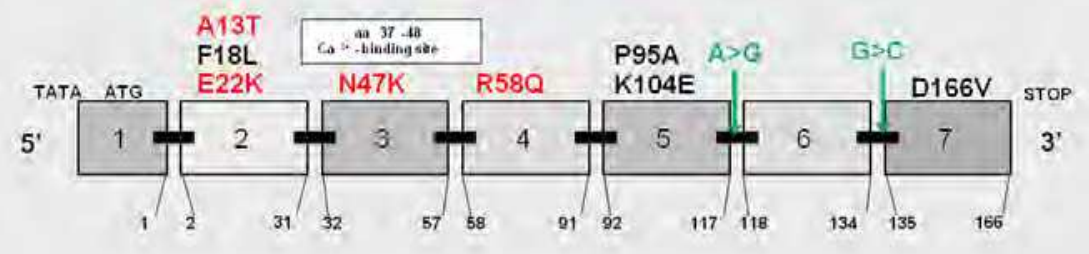

Fig. 2. Exon organization of the MYL2 gene (chromosome 12q23-q24.3) and FHC-linked mutations in human ventricular RLC (Swiss-Prot: P10916). Labeled in red, FHC mutations described in this review; in black, other identified RLC mutations; and in green, intronic splice site mutations: A (adenine) $\rightarrow \mathrm{G}$ (guanine) transversion in intron 5 and $\mathrm{G} \rightarrow \mathrm{C}$ (cytosine) transversion in intron 6.

The F18L mutation arises from a replacement of a bulky nonpolar and hydrophobic phenylalanine by the small uncharged and nonpolar leucine residue. It was found in three unrelated French families and is associated with a classic phenotype of left ventricular wall thickening and electrocardiographic (ECG) abnormities (Richard et al., 2003).

The E22K mutation results from a substitution of a negatively charged glutamate with a positively charged lysine leading to potential alterations in the net charge and polarity of the mutation-bearing domain of RLC. The mutation was first identified in three persons (two brothers and one non-related individual) from two unrelated families screened together with 399 unrelated HCM patients (Poetter et al., 1996). Subsequent studies by Kabaeva, et al. identified seven individuals in a German family carrying the mutation. However, only four patients suffered from HCM while the phenotype of the remaining individuals was defined as "uncertain" (Kabaeva et al., 2002). Based on the latest clinical reports on this mutation, it is known to be associated with moderate septal hypertrophy, late onset of clinical manifestations, and benign to severe disease outcomes.

The N47K mutation results from the replacement of a polar uncharged asparagine residue by the positively charged lysine. It was first discovered in an individual of Danish descent (Andersen et al., 2001). This mutation is associated with a late onset of the disease and a rapidly progressing phenotype. The proband was diagnosed with HCM at the age of 60, and quickly progressed to a severe hypertrophic phenotype and diastolic dysfunction. It was interesting that septal hypertrophy of this patient increased rapidly (from $31 \mathrm{~mm}$ to $45 \mathrm{~mm}$ ) 
in the two years after diagnosis. In 2005, a Danish patient carrying both N47K and a $\beta$ cardiac myosin heavy chain mutation was identified. The proband bearing both of these mutations displayed a more severe phenotype than patients with either mutation alone (Hougs et al., 2005). However, no incidence of sudden cardiac death (SCD) associated with this mutation has yet been reported.

The R58Q mutation occurs when the bulky positively charged arginine is replaced by an uncharged but polar glutamine. It was first discovered by Flavigny, et al. in 1998 in three unrelated French families with HCM (Flavigny et al., 1998). The mutation was associated with a classic form of FHC characterized by left ventricular wall thickness, abnormal ECG findings and SCD (Flavigny et al., 1998). In 2002, Kabaeva, et al. detected this R58Q mutation in a German proband with a clinical phenotype of moderate septal hypertrophy, early onset of disease and premature SCD (Kabaeva et al., 2002). In 2003, the R58Q mutation was once more identified in two independent population studies (from France and Sweden), and again was associated with a malignant disease phenotype (Morner et al., 2003; Richard et al., 2003). Out of all identified FHC RLC mutations, the R58Q mutation was found to be the most prevalent, occurring independently in multiple families with different ethnic backgrounds. The mutation is associated with a phenotype of severe cardiac hypertrophy and multiple incidences of SCD.

The P95A mutation occurs when a bulky hydrophobic proline residue is substituted with a smaller alanine residue. It was discovered together with the A13T and E22K mutations in an American family and shares a rare clinical phenotype, similar to that of A13T and E22K positive patients (Poetter et al., 1996).

The K104E mutation results from a replacement of the positively charged lysine with the negatively charged glutamic acid. The mutation was first observed in a Danish family and was mistakenly reported as L103E (Andersen et al., 2001). The parents carrying this mutation were asymptomatic with a normal ECG pattern. However, their son was diagnosed with pronounced septal hypertrophy at the age of 17 and progressed to diastolic dysfunction. His sister, 42 years old, was also positive for the mutation, but no typical hypertrophic phenotype was observed in her case. This mutation is associated with pronounced septal hypertrophy and diastolic filling abnormalities.

The D166V mutation occurs when a negatively charged aspartic acid is substituted with a bulky polar valine residue. This mutation was identified in a French proband, with the potential to cause SCD at a young age. It was first mistakenly presented as D166L in Richard, et al., 2003 and later corrected to D166V (Richard et al., 2003; 2004). Similar to $\mathrm{R} 58 \mathrm{Q}$, this mutation is associated with a malignant disease phenotype and SCD.

Intron mutations: Intron 6-1 G>C mutation (IVS 6-1) was discovered along with K104E in the Danish population and is associated with pronounced septal hypertrophy (Andersen et al., 2001). The other intronic mutation 5-2 A $>$ G, (IVS 5-2) was first discovered in the French population and is associated with a malignant form of FHC (Richard et al., 2003). The mutation is predicted to lead to a premature codon termination.

The clinical phenotype associated with FHC-linked mutations in the regulatory light chain and current to date literature citations are illustrated in Table 1.

This review focuses on the functional phenotypes associated with five (A13T, E22K, N47K, R58Q and D166V) RLC mutations extensively studied in vitro using RLC-mutant reconstituted muscle systems and in vivo, using cardiac muscle preparations from transgenic mice expressing FHC-RLC mutations. 


\begin{tabular}{|c|c|c|c|}
\hline $\begin{array}{l}\text { Mutation in } \\
\text { RLC }\end{array}$ & Clinical phenotype & Population & Major findings \\
\hline A13T & $\begin{array}{l}\text { Massive hypertrophy } \\
\text { of cardiac papillary } \\
\text { muscles, mid-cavity } \\
\text { left ventricular } \\
\text { obstruction, } \\
\text { pronounced septal and } \\
\text { ventricular } \\
\text { hypertrophy and } \\
\text { diastolic filling } \\
\text { abnormalities }\end{array}$ & $\begin{array}{l}\text { Danish } \\
\text { (Andersen et } \\
\text { al., 2001; } \\
\text { Hougs et al., } \\
\text { 2005); } \\
\text { American } \\
\text { (Poetter et al., } \\
1996)\end{array}$ & $\begin{array}{l}\text { Mutation-induced changes in } \alpha \text {-helical content and in } \\
\mathrm{Ca}^{2+} \text { binding properties of RLC (Szczesna et al., } \\
\text { 2001). } \\
\text { No change in } \mathrm{Ca}^{2+} \text { sensitivity of myofibrillar ATPase } \\
\text { activity (Szczesna et al., 2001). } \\
\text { Increased force production in skinned papillary } \\
\text { muscle fibers from Tg-A13T mice (unpublished } \\
\text { data). } \\
\text { Histopathological changes in left ventricles and inter- } \\
\text { ventricular septa of Tg-A13T mice (unpublished } \\
\text { data) }\end{array}$ \\
\hline F18L & $\begin{array}{l}\text { Classic form of HCM - } \\
\text { increased left } \\
\text { ventricular wall } \\
\text { thickness, abnormal } \\
\text { ECG findings, no mid } \\
\text { left ventricular } \\
\text { obstruction }\end{array}$ & $\begin{array}{l}\text { French } \\
\text { (Flavigny et al., } \\
\text { 1998; Richard } \\
\text { et al., 2003) }\end{array}$ & $\begin{array}{l}\text { Decrease in } \mathrm{Ca}^{2+} \text { binding affinity to RLC (Szczesna et } \\
\text { al., 2001). } \\
\text { Increase in a-helical content of RLC (Szczesna et al., } \\
\text { 2001). } \\
\text { Decrease in } \mathrm{Ca}^{2+} \text { sensivity of myofibrillar ATPase } \\
\quad \text { activity (Szczesna-Cordary et al., 2004a). } \\
\text { Compromised maximal tension, cooperativity and } \mathrm{Ca}^{2+} \\
\text { sensitivity of force (Roopnarine, 2003). }\end{array}$ \\
\hline $\mathrm{E} 22 \mathrm{~K}$ & $\begin{array}{l}\text { Moderate septal } \\
\text { hypertrophy, late onset } \\
\text { of clinical } \\
\text { manifestation or no } \\
\text { symptoms of FHC } \\
\text { (Kabaeva). Also } \\
\text { associated with } \\
\text { massive hypertrophy } \\
\text { of cardiac papillary } \\
\text { muscles and adjacent } \\
\text { venstricular tissue } \\
\text { causing midcavity } \\
\text { obstruction (Poetter) }\end{array}$ & $\begin{array}{l}\text { German } \\
\text { (Kabaeva et al., } \\
\text { 2002), } \\
\text { American } \\
\text { (Poetter et al., } \\
\text { 1996) }\end{array}$ & $\begin{array}{l}\text { Protein non-phosphorylatable (Szczesna et al., 2001). } \\
\text { Mutation induced changes in } \alpha \text {-helical content and } \\
\quad \mathrm{Ca}^{2+} \text { binding properties of RLC (Szczesna et al., } \\
\text { 2001). } \\
\text { Increase in } \mathrm{Ca}^{2+} \text { sensitivity of force (Levine et al., 1998; } \\
\text { Roopnarine, 2003; Szczesna-Cordary et al., 2004a) } \\
\text { and decrease in maximal ATPase and force in } \\
\text { skinned fibers from Tg-E22K mice (Szczesna- } \\
\text { Cordary et al., 2007). } \\
\text { No effect on cross-bridge kinetics (Szczesna-Cordary et } \\
\text { al., 2007; (Dumka et al., 2006). } \\
\text { Enlarged inter-ventricular septa and papillary muscles } \\
\text { (Szczesna-Cordary et al., 2005). } \\
\text { No hypertrophy detected in Tg-E22K mice (Sanbe et al., } \\
\text { 2000). } \\
\text { No changes in ECG (Szczesna-Cordary et al., 2005). }\end{array}$ \\
\hline N47K & $\begin{array}{l}\text { Pronounced } \\
\text { interventricular } \\
\text { (septal) and papillary } \\
\text { musle hypertrophy; } \\
\text { relatively high } \\
\text { midventricular flow } \\
\text { gradient, diastolic } \\
\text { filling abnormalities; } \\
\text { late onset disease with } \\
\text { a rapidly progressing } \\
\text { phenotype }\end{array}$ & $\begin{array}{l}\text { Danish } \\
\text { (Andersen et } \\
\text { al., 2001; } \\
\text { Hougs et al., } \\
\text { 2005) }\end{array}$ & $\begin{array}{l}\text { Abolished } \mathrm{Ca}^{2+} \text { binding to RLC (Szczesna-Cordary et } \\
\text { al., 2004a). } \\
\text { Increased Ca }{ }^{2+} \text { sensivity of myofibrillar ATPase activity } \\
\text { (Szczesna-Cordary et al., 2004a). } \\
\text { No change in pCa50 of force (Szczesna-Cordary et al., } \\
\text { 2004a). } \\
\text { Prolonged Ca }{ }^{2+} \text { transient with no change in force } \\
\text { transients in intact papillary muslces (Wang et al., } \\
\text { 2006). } \\
\text { Decreased isometric force in N47K-myosin based in } \\
\text { vitro motility assays (Greenberg et al., 2009). } \\
\text { Reduction in force and power output under loaded } \\
\text { conditions (Greenberg et al., 2010). } \\
\text { Decreased cardiac function in isolated perfused } \\
\text { working hearts (Abraham et al., 2009). }\end{array}$ \\
\hline
\end{tabular}




\begin{tabular}{|c|c|c|c|}
\hline $\begin{array}{c}\text { Mutation in } \\
\text { RLC }\end{array}$ & Clinical phenotype & Population & Major findings \\
\hline R58Q & $\begin{array}{l}\text { Malignant FHC } \\
\text { phenotype, early onset } \\
\text { of clinical } \\
\text { manifestation and high } \\
\text { incidence of premature } \\
\text { SCD; classic form of } \\
\text { HCM - increased left } \\
\text { ventricular wall } \\
\text { thickness and } \\
\text { abnormal ECG } \\
\text { findings }\end{array}$ & $\begin{array}{l}\text { German } \\
\text { (Kabaeva et al., } \\
\text { 2002), French } \\
\text { (Flavigny et al., } \\
\text { 1998; Richard } \\
\text { et al., 2003), } \\
\text { Swedish ( } \\
\text { Morner et al., } \\
\text { 2003) }\end{array}$ & $\begin{array}{l}\text { Abolished Ca }{ }^{2+} \text { binding to RLC, which was restored } \\
\text { upon RLC phosphorylation. (Szczesna et al., } \\
\text { 2001). } \\
\text { Mutation induced increase in a-helical content of RLC } \\
\text { (Szczesna et al., 2001). } \\
\text { Increased Ca+ sensitivity of force (Szczesna-Cordary et } \\
\text { al., 2004a), and Ca' and force transient in intact } \\
\text { papillary muscles (Wang et al., 2006). } \\
\text { Higher ATPase rate and increased activation at } \\
\text { submaximal Ca² (Greenberg et al., 2009). } \\
\text { Decreased skewness and kurtosis of fluctuations } \\
\text { during contraction (Borejdo et al., 2010). } \\
\text { Decreased force (Abraham et al., 2009; Greenberg et al., } \\
\text { 2010; Greenberg et al., 2009; Wang et al., 2006). } \\
\text { Reduced level of endogenous RLC phosphorylation } \\
\text { (Abraham et al., 2009). } \\
\text { Decreased cardiac function in isolated perfused } \\
\text { working hearts (Abraham et al., 2009). } \\
\text { Alterations in diastolic transmitral velocities and } \\
\text { increased deceleration time, indicative of diastolic } \\
\text { dysfunction (Abraham et al., 2009). }\end{array}$ \\
\hline P95A & $\begin{array}{l}\text { Rare clinical } \\
\text { phenotype, similar to } \\
\text { E22K and A13T, of } \\
\text { midventricular } \\
\text { obstruction }\end{array}$ & $\begin{array}{l}\text { American } \\
(\text { Poetter et al., } \\
1996)\end{array}$ & $\begin{array}{l}\text { Mutation-induced decrease in } \mathrm{Ca}^{2+} \text { binding to RLC } \\
\text { (Szczesna et al., 2001). } \\
\text { No significant effect on tension, } \mathrm{Ca}^{2+} \text { sensitivity, or } \\
\text { cooperativity in P95A-reconstituted fibers } \\
\text { (Roopnarine, 2003). }\end{array}$ \\
\hline K104E & $\begin{array}{l}\text { Pronounced septal } \\
\text { hypertrophy and } \\
\text { diastolic filling } \\
\text { abnormalities }\end{array}$ & $\begin{array}{l}\text { Danish } \\
\text { (Andersen et } \\
\text { al., 2001) }\end{array}$ & $\begin{array}{l}\text { Impaired interaction with IQ-MHC peptide (Szczesna- } \\
\text { Cordary et al., 2004b). } \\
\text { Slight decrease in binding to RLC-depleted porcine } \\
\text { myosin (Huang et al., 2011). }\end{array}$ \\
\hline D166V & $\begin{array}{l}\text { Malignant FHC } \\
\text { phenotype - poor } \\
\text { prognosis and SCD at } \\
\text { young age }\end{array}$ & $\begin{array}{l}\text { French } \\
\text { (Richard et al., } \\
2003 ; 2004)\end{array}$ & $\begin{array}{l}\text { Decrease in maximal force and large increase in } \mathrm{Ca}^{2+} \\
\text { sensitivity in papillary muscle fibers from Tg- } \\
\text { D166V mice (Kerrick et al., 2009). } \\
\text { Decrease in } \mathrm{Ca}^{2+} \text { sensitivity of force upon } \\
\text { phosphorylation (Muthu et al., 2011). } \\
\text { Slower cross bridge kinetics (Borejdo et al., 2010; } \\
\quad \text { Mettikolla et al., 2009; Muthu et al., 2010). } \\
\text { Reduced level of endogenous RLC phosphorylation } \\
\quad \text { (Kerrick et al., 2009). } \\
\text { Severe fibrotic lesions in older Tg-D166V mouse hearts } \\
\quad \text { (Kerrick et al., 2009). }\end{array}$ \\
\hline IVS6-1 & $\begin{array}{l}\text { Pronounced proximal } \\
\text { septal hypertrophy }\end{array}$ & $\begin{array}{l}\text { Danish } \\
\text { (Andersen et } \\
\text { al., 2001) }\end{array}$ & $G>C$ transversion in Intron 6 (Andersen et al., 2001). \\
\hline IVS5-2 & Malignant prognosis & $\begin{array}{l}\text { French } \\
\text { (Richard et al., } \\
2003 \text { ) }\end{array}$ & $\begin{array}{l}\text { Donor-site splice mutation }(A>G) \text { in Intron } 5 \text { predicted } \\
\text { to lead to a premature termination codon (Richard } \\
\text { et al., 2003). }\end{array}$ \\
\hline
\end{tabular}

Table 1. Summary of clinical and functional phenotypes of FHC mutations in the regulatory light chain (RLC). 


\section{Effect of FHC mutations on the secondary RLC structure and calcium binding properties}

This review reports on the studies that were conducted to elucidate the structural and functional effects of FHC-linked RLC mutations. The RLC protein, labeled in red in Fig. 3, wraps around the myosin heavy chain (dark blue) and connects the myosin head with the myosin rod region. The three-dimensional (3D) structure of the RLC demonstrates the close proximity of the FHC mutations to either the phosphorylation site of RLC (Ser-15) or the $\mathrm{Ca}^{2+}$ binding site (amino acids 37-48 in the sequence of human ventricual RLC) (Fig. 3). The presence of these two important RLC domains in the RLC structure prompted the studies aimed at understanding the effects of the FHC mutations on $\mathrm{Ca}^{2+}$ binding to RLC and to determine how MLCK-dependent phosphorylation of RLC is affected in FHC disease. Furthermore, additional studies were conducted to determine the effect of FHC-linked RLC mutation and phosphorylation on the secondary RLC structure.

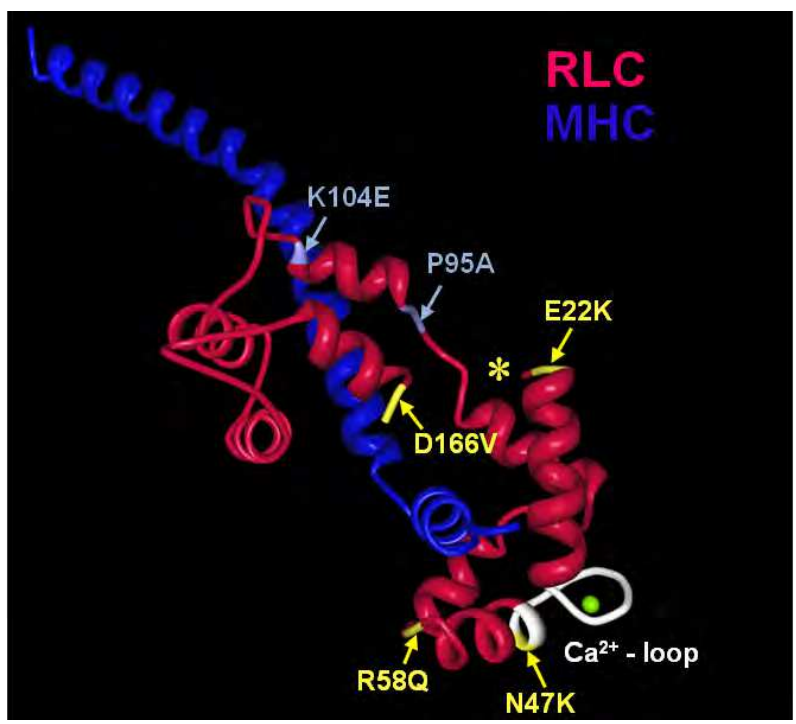

Fig. 3. Structure of the regulatory domain of scallop myosin (1WDC) (Houdusse \& Cohen, 1996): Indicated are the FHC mutations, $\mathrm{Ca}^{2+}-\mathrm{Mg}^{2+}$ binding site and the phosphorylation site. The MHC (myosin heavy chain) is labeled in dark blue, and the RLC (regulatory light chain) in red. Asterisks $\left(^{*}\right)$ depict the predicted location of A13T and F18L mutations and Ser-15 phosphorylation site (the region of RLC which is not resolved in all available vertebrate myosin crystal structures).

\subsection{Circular dichroism study}

In order to test the effect of RLC mutations on the secondary structure of RLC, far-UV circular dichroism (CD) spectra measurements were performed and the a-helical content determined (Szczesna-Cordary et al., 2004a; Szczesna et al., 2001). Far-UV CD spectra were obtained using a 1-mm path quartz cell in a Jasco J-720 spectropolarimeter and were recorded at $195-250 \mathrm{~nm}$. Mean residue ellipticity $\left([\theta]_{\mathrm{MRE}}\right.$, in degrees $\left.{ }^{*} \mathrm{~cm}^{2} / \mathrm{dmol}\right)$ for the spectra were calculated using the following equation: 


\section{$[\theta]_{\mathrm{MRE}}=[\theta] /\left(10^{*} \mathrm{Cr} * \mathrm{l}\right)$}

where $[\theta]$ is the measured ellipticity in millidegrees, $\mathrm{Cr}$ is the mean residue molar concentration, and $l$ is the path length in $\mathrm{cm}$.

The a-helical content for each mutant was calculated using the standard equation for [ $\theta]$ at $222 \mathrm{~nm}$ (Chen \& Yang, 1971):

$$
[\theta]_{222}=-30,000 * \mathrm{f}_{\mathrm{H}}-2340
$$

where $f_{H}$ is the fraction of a-helical content $\left(f_{H} * 100\right.$, expressed in \%). Any change above $2 \%$ in the a -helical content was considered statistically significant.

As the mutations lie in the proximity of the phosphorylation site (Ser-15) and/or the $\mathrm{Ca}^{2+}$ $\mathrm{Mg}^{2+}$ binding site (Fig. 3), the a-helical content was measured in the absence (Apo) and presence of $\mathrm{Ca}^{2+}$. In addition, data were collected for phosphorylated RLC (Table 2).

\begin{tabular}{|l|l|l|ll|l|}
\hline \multicolumn{1}{|c|}{ Protein } & \multicolumn{1}{|c|}{ Apo } & \multicolumn{1}{c|}{$+\mathbf{C a}^{2+}$} & \multicolumn{1}{c|}{$+\mathbf{P}+\mathbf{C a}^{2+}$} \\
\hline RLC-WT & 18 & 23 & 18 & 18 \\
\hline A13T & 29 & 25 & 19 & 18 \\
\hline E22K & 24 & 20 & \multicolumn{2}{|c|}{ No phosphorylation } \\
\hline N47K & 18.7 & ND & ND & ND \\
\hline R58Q & 20 & 22 & 20 & 28 \\
\hline P95A & 19 & 23 & ND & ND \\
\hline
\end{tabular}

Table 2. Effect of phosphorylation and $\mathrm{Ca}^{2+}$-binding on the a-helical content of RLC expressed in \%. (ND: not determined) (Szczesna-Cordary et al., 2004a; Szczesna et al., 2001).

Based on these results, it was determined that under Apo (no metal) conditions, with the exception of the N47K and P95A mutants, the FHC-linked RLC mutation led to an increased a-helical content compared to RLC-WT (Szczesna-Cordary et al., 2004a; Szczesna et al., 2001). It was also observed that upon binding of $\mathrm{Ca}^{2+}$ to $\mathrm{RLC}$, the a-helical content was significantly increased in all proteins including WT (Table 2), suggesting that binding of calcium to RLC could be conformation dependent. Interestingly, upon phosphorylation, A13T displayed a significant decrease in the a-helical content compared to nonphosphorylated A13T in the presence or absence of $\mathrm{Ca}^{2+}$. Therefore, phosphorylation of the A13T mutant rescued the secondary structure of the mutant bringing the a-helical content to the level of RLC-WT. The authors concluded that phosphorylation of RLC could reverse the detrimental effect of FHC brought about by the A13T mutation (Szczesna et al., 2001).

\subsection{Calcium binding study}

As shown above in Fig. 3, the N-terminal domain of RLC contains the EF-hand $\mathrm{Ca}^{2+}-\mathrm{Mg}^{2+}$ binding site, similar to the EF-hand $\mathrm{Ca}^{2+}$-sites present in troponin $\mathrm{C}(\mathrm{TnC})$, parvalbumin, calmodulin (CaM) and essential light chain (ELC). To test how these mutations affect calcium binding to the RLC, flow dialysis experiments were conducted and the $\mathrm{Ca}^{2+}$ association/dissociation constant was determined (Szczesna et al., 2001). Radio-labeled substrate $\left({ }^{45} \mathrm{Ca}^{2+}\right)$ was first added into a chamber containing a fixed amount of RLC. Once the reaction reached steady-state, radio-labeled ${ }^{45} \mathrm{Ca}^{2+}$ was chased by unlabeled $\mathrm{Ca}^{2+}$. The concentrations of bound-Ca ${ }^{2+}$ and free-Ca ${ }^{2+}$ were determined and the $\mathrm{K}_{\mathrm{Ca}}$ values analyzed. Calcium association constant $\mathrm{K}_{\mathrm{Ca}}$ was extrapolated from the following equation:

$$
\mathrm{C}_{\text {Ca-bound }} / \mathrm{C}_{\text {Ca-free }} / \mathrm{C}_{\mathrm{p}}=-\mathrm{K}_{\mathrm{Ca}}{ }^{*} \mathrm{C}_{\text {Ca-bound }} / \mathrm{C}_{\mathrm{p}}+\mathrm{n}^{*} \mathrm{~K}_{\mathrm{Ca}}
$$


$\mathrm{C}_{\mathrm{Ca}-\text { bound }}$ and $\mathrm{C}_{\mathrm{Ca}-\text {-ree }}$ represent the concentration of the bound and free metal, respectively, $\mathrm{C}_{\mathrm{p}}$ is the concentration of the protein, $\mathrm{n}$ is the total number of $\mathrm{Ca}^{2+}$ binding sites, and $\mathrm{K}_{\mathrm{Ca}}$ is the $\mathrm{Ca}^{2+}$ binding affinity. $1 / K_{C a}$ represents the apparent calcium dissociation constant $K_{d}$ (in $\left.\mu M\right)$. The effect of the mutations on calcium binding to recombinant human cardiac RLC and FHClinked mutants is summarized in Table 3 (Szczesna et al., 2001). Table 3 also summarizes the effect of FHC RLC mutations on calcium binding to myofibrils and skinned muscle fibers reconstituted with WT or FHC-mutant proteins (Szczesna-Cordary et al., 2004a).

\begin{tabular}{|c|c|c|c|}
\hline RLC protein & $\begin{array}{c}\text { Isolated RLC (no } \\
\left.\mathrm{Mg}^{2+}\right) \\
(\mu M)\end{array}$ & $\begin{array}{c}\text { Myofibrils" } \\
\left(2 \mathrm{mM} \mathrm{Mg^{2+ }}\right) \\
(\mu M)\end{array}$ & $\begin{array}{c}\text { Fibers }^{\#} \\
\left(\begin{array}{c}\text { mMMg } \\
\left.\mathrm{mMM}^{2+}\right) \\
(\mu M)\end{array}\right.\end{array}$ \\
\hline RLC-WT & $1.50 \pm 0.02$ & $0.200 \pm 0.009$ & $2.88 \pm 0.19$ \\
\hline A13T & $4.85 \pm 0.31$ & $0.191 \pm 0.015$ & $3.02 \pm 0.06$ \\
\hline E22K & $25.64 \pm 3.48$ & $0.178 \pm 0.001$ & $2.63 \pm 0.10$ \\
\hline N47K & No binding & $0.141 \pm 0.009$ & $2.51 \pm 0.10$ \\
\hline R58Q & No binding & $0.170 \pm 0.004$ & $2.19 \pm 0.10$ \\
\hline P95A & $4.74 \pm 1.05$ & $0.200 \pm 0.011$ & $2.75 \pm 0.25$ \\
\hline
\end{tabular}

Table 3. Apparent $K_{d}\left(1 / K_{C a}\right)$ of isolated RLC-WT and FHC mutants and in mutantreconstituted myofibrils and skinned porcine muscle fibers ( ${ } \mathrm{K}_{\mathrm{d}}$ calculated from the $\mathrm{pCa} \mathrm{a}_{50}$ values \pm S.E.) (Szczesna-Cordary et al., 2004a).

Flow dialysis experiments with recombinant RLC-WT and FHC-mutants showed that A13T and P95A decreased the $\mathrm{K}_{\mathrm{Ca}} \sim 3$-fold, whereas E22K, N47K and $\mathrm{R} 58 \mathrm{Q}$, changed the $\mathrm{Ca}^{2+}$ binding properties in a more drastic way. Compared with RLC-WT, the E22K mutation decreased the $\mathrm{K}_{\mathrm{Ca}}$ value by $\sim 17$-fold, whereas both $\mathrm{N} 47 \mathrm{~K}$ and R58Q mutations eliminated $\mathrm{Ca}^{2+}$ binding to RLC (Table 3) (Szczesna et al., 2001). These three $\mathrm{Ca}^{2+}$ binding site mutants also showed an increase in the $\mathrm{Ca}^{2+}$ sensitivity of myofibrillar ATPase activity and force development, with R58Q demonstrating significantly higher $\mathrm{K}_{\mathrm{Ca}}$ compared to RLC WT-reconstituted muscle preparations (Table 3) (Szczesna-Cordary et al., 2004a). Interestingly, flow dialysis studies showed that the restricted ability of the R58Q mutant to bind calcium was restored upon phosphorylation (Szczesna et al., 2001). These studies suggested that the phosphorylation and $\mathrm{Ca}^{2+}$ binding to human cardiac RLC are important for physiological function and that alteration of any of these properties may contribute to the development of hypertrophic cardiomyopathy. Results from the in vitro studies prompted generation of the animal models of FHC-linked RLC mutations and subsequent investigations of their functional effects in vivo. Studies included experiments performed at different levels of complexity; from single molecules to organized sarcomeres in muscle fibers and to the organ and organism levels. Transgenic mice carrying FHC RLC mutations were used in these experiments.

\section{Animal models of FHC}

\subsection{Generation of transgenic mice}

Transgenic (Tg) mouse models expressing wild-type (WT) and FHC-mutated human ventricular cardiac RLC (A13T, E22K, N47K, R58Q and D166V) were generated using the $\alpha$ myosin heavy chain $(\alpha-\mathrm{MHC})$ promoter (clone 26, a generous gift from Dr J. Robbins, Cincinnati Children's Hospital Medical Center, Cincinnati, OH, USA). All of the founders 
were bred to non-transgenic (NTg) B6SJL mice. Two types of Tg-WT mice were generated as necessary controls for the transgenic mutant mice; one expressing human ventricular cardiac RLC and another expressing the human ventricular cardiac RLC along with a myctag sequence. The following transgenic mouse models were produced and used for the experiments described in this review: WT, A13T, E22K, N47K, R58Q and D166V.

\subsection{Phenotypic characterization of FHC-RLC animal models}

\subsubsection{Assessment of cardiac hypertrophy by HW/BW ratio}

The heart weight to body weight (HW/BW) ratio was used to examine all generated FHC RLC animal models for heart hypertrophy. Fig. 4 demonstrates the HW/BW ratios determined for mice carrying A13T, D166V, N47K and R58Q mutations. No evidence of hypertrophy was observed in the majority of mutant mice compared to WT (Kerrick et al., 2009; Wang et al., 2006). Differences in HW/BW were only seen between the hearts from Tg-N47K versus Tg-WT mice, but no statistically significant changes were observed.

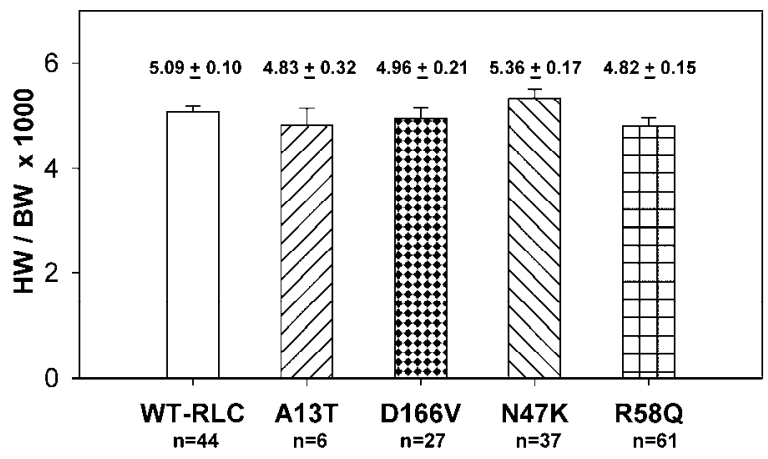

Fig. 4. Heart weight to body weight ratios in transgenic RLC animal models: P-values for all mutant mice (A13T, D166V, N47K and R58Q) versus WT-RLC were $>0.05$.

These results suggested that the histopathological and functional changes observed due to these mutations (discussed later) may be more indicative of the FHC phenotype than overall heart hypertrophy.

\subsubsection{Histopathology}

The most specific histological feature of hypertrophic cardiomyopathy is an extensive disorganization of the myocyte structure (myocyte disarray). Often observed are abnormally branched (Y-shaped) myocytes with adjacent myocytes arranged perpendicularly or obliquely to each other (Binder et al., 2005). Histological studies were performed to characterize the mutation specific cardiac phenotype at the level of the Tg mouse model and to establish a correlation with the phenotypes observed in patients harboring these FHC RLC mutations. Histopatological evaluation of the hearts from Tg-A13T, Tg-E22K, Tg-WT and NTg mice is presented in Fig. 5. The upper panel shows longitudinal sections of the whole hearts from Tg-A13T versus control mice and the lower panel presents Tg-E22K mouse hearts. As indicated with arrows, a significantly larger LV and inter-ventricular septal mass was observed for both Tg-A13T (unpublished data) and Tg-E22K (SzczesnaCordary et al., 2005) mice compared with Tg-WT or NTg littermates. 


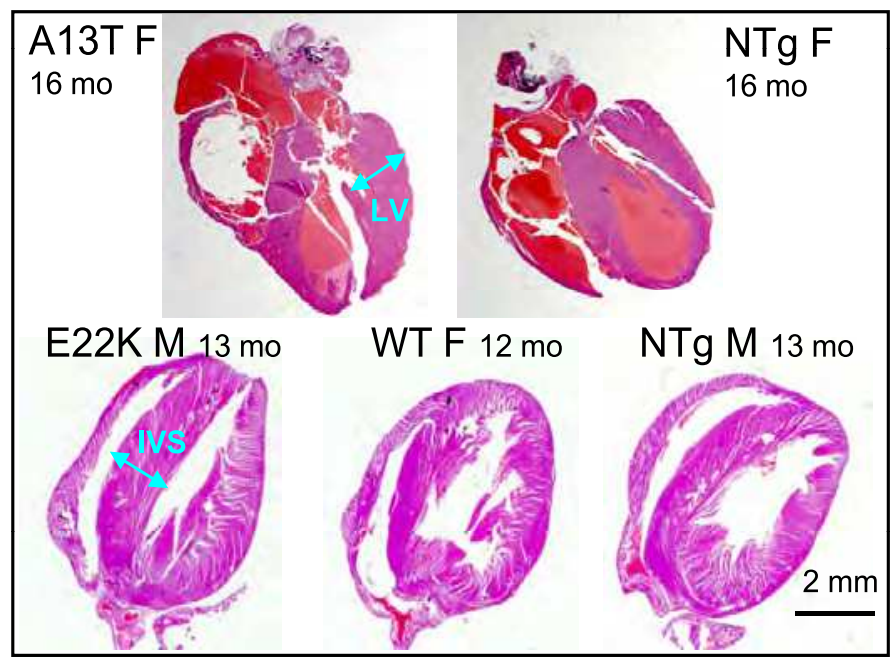

Fig. 5. Longitudinal sections of whole mouse hearts stained with hematoxylin and eosin $(\mathrm{H}$ \& E). Upper panel: Tg-A13T versus NTg controls (unpublished data). Bottom panel: Tg-E22K and controls (Szczesna-Cordary et al., 2005). Abbreviations: F, female; M, male; mo, age of mice in months; LV, left ventricle; IVS, interventricular septum.

Gross morphological evaluation of the hearts from Tg-A13T and Tg-E22K mice revealed a common phenotype of enlarged inter-ventricular septa (Fig. 6), a phenotype observed in patients carrying the A13T and E22K mutations (Poetter et al., 1996). Interestingly, in another study transgenic mice expressing the E22K mutation did not show any features of the FHC disease despite almost total replacement of the endogenous WT RLC with mutant RLC (Sanbe et al., 2000). No hypertrophy was detected in mature adult animals either when chamber weights were determined or at the cellular level (Sanbe et al., 2000).

Other RLC FHC mutant mice were examined for histopathological abnormalities, and longitudinal ventricular sections were stained with hematoxylin and eosin to detect any tissue disorganization and with Masson's trichrome to determine the presence of abnormal collagen deposits and fibrosis. As shown in Fig. 6, mice carrying the malignant R58Q mutation manifested histopathological changes (myofibrillar disarray and abnormal clustering of nuclei) as early as at 4 months of age (Fig. 6A, B). The changes seen in older ( $\sim 17$ months old) mice, presented in Wang et al. were profound in both Tg-R58Q and TgN47K mice (Wang et al., 2006). The changes observed in Tg-N47K mice correlated with the phenotype found in humans demonstrating a late onset of disease with a rapidly progressing phenotype. Similarly, examination of the older ( 17 months of age) Tg-D166V mice revealed severe fibrotic lesions present in the left ventricles compared with age matched Tg-WT and NTg littermates (Fig. 6C). Morphological changes found in the older Tg-D166V mice suggest that the ventricles of the FHC Tg-D166V mice undergo temporal phenotypic changes that are not present in the younger mice $(\sim 7$ months of age) (Kerrick et al., 2009). These studies suggested that while in Tg-N47K and Tg-D166V animals the functional changes induced by the mutations (evident at 3-6 months of age in mice) may precede the development of any detrimental morphological changes; the histopathological changes observed in Tg-R58Q mice paralleled the functional abnormalities. 

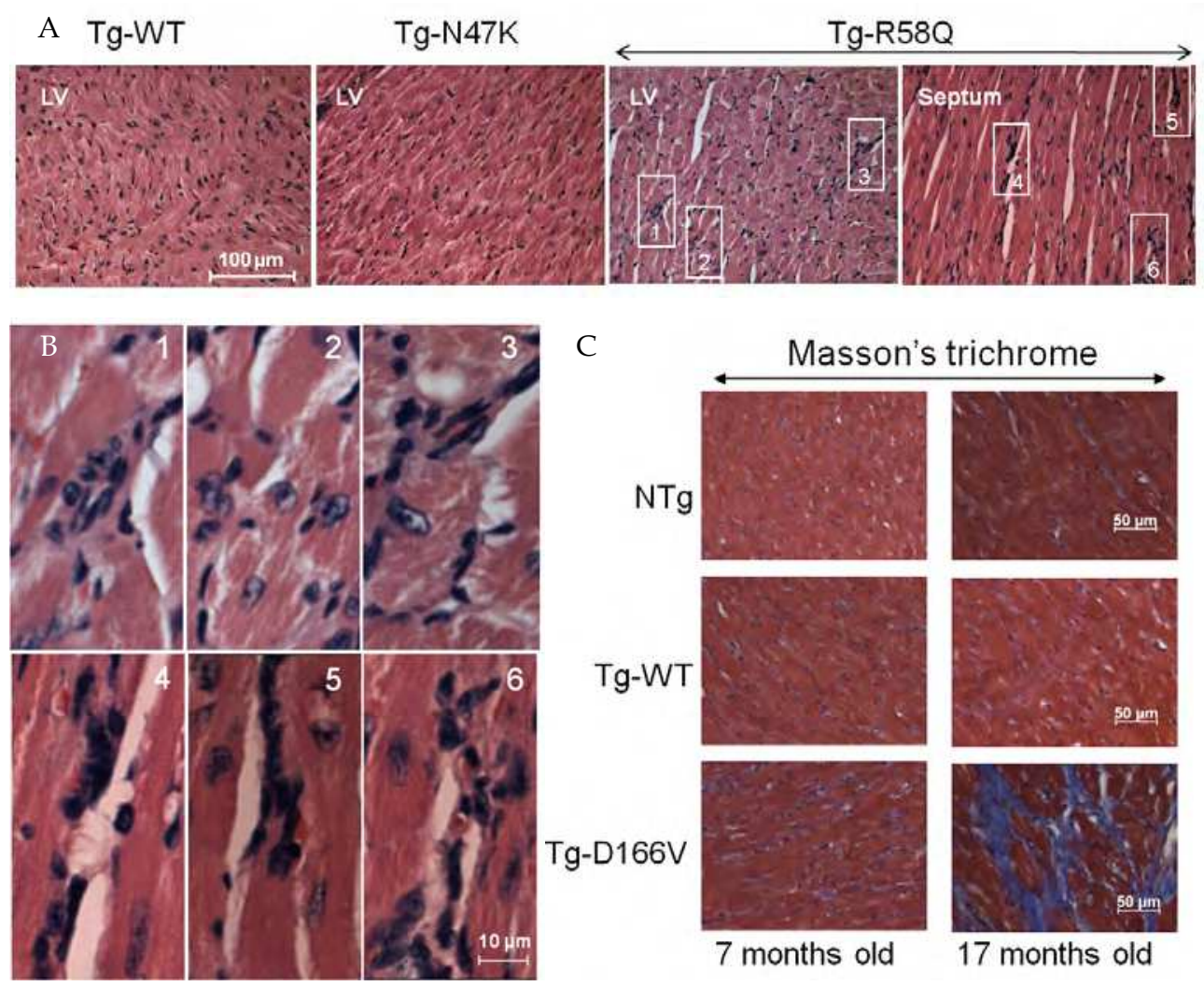

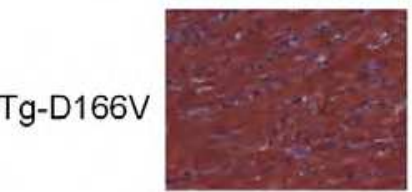

7 months old

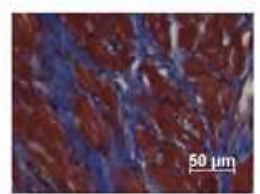

17 months old

Fig. 6. Histopathology of transgenic mouse hearts. (A) The hearts of representative 4 monthold mice from Tg-WT, Tg-N47K and Tg-R58Q mice were stained with hematoxylin and eosin. Note that nuclei stain blue with hematoxylin, whereas the cells stain pink/red with eosin. Scale bar, $100 \mu \mathrm{m}$. (B) Enlarged views of the left ventricle and septal tissues of Tg-R58Q hearts. Scale bar, $10 \mu \mathrm{m}$. As indicated, clusters of nuclei could be clearly observed in Tg-R58Q tissues compared to control samples suggesting occurrences of the R58Q-mediated degeneration in Tg-R58Q myocardium. (C) Microscopic views of left ventricles from Tg-D166V and control TgWT and NTg mice stained with Masson's trichrome stain (Kerrick et al., 2009). Note the severe fibrotic lesions in the myocardium of older 17 months old Tg-D166V mice. Scale bar, $50 \mu \mathrm{m}$.

\subsubsection{Echocardiography}

Echocardiography, a test in which ultrasound measurements are used to examine the heart, is the least invasive method available to screen for cardiac hypertrophy. The echocardiogram allows for detailed morphological and functional assessment of the heart. Echocardiography examination performed on Tg-E22K mice did not show any major differences between transgenic E22K and control WT and/or NTg hearts (Szczesna-Cordary et al., 2005).

Doppler echocardiography, another technique of ultrasound examination is used to look at how blood flows through the heart chambers, heart valves, and blood vessels. It allows determination of the velocity and direction of blood flow by utilizing the Doppler effect. 
Based on the cellular findings, Abraham et al. hypothesized that a malignant FHC phenotype associated with the R58Q mutation could be related to diastolic dysfunction of the R58Q-mutated myocardium (Abraham et al., 2009). Global diastolic haemodynamics were evaluated using transmitral Doppler velocities in Tg-R58Q and Tg-N47K mice and compared to controls (NTg and Tg-WT). An apical four-chamber view of the heart was obtained. A pulsed Doppler sample was placed at the tip of the mitral leaflets and transmitral early (E) and late (A) diastolic velocities and the deceleration time were measured and used as noninvasive indicators of global diastolic function (Abraham et al., 2009). Interestingly, alterations in diastolic transmitral velocities and prolonged deceleration time were only noted in Tg-R58Q myocardium (Fig. 7). The authors suggested that the malignant FHC phenotype associated with R58Q could be related to abnormal relaxation and diastolic dysfunction of the mutated myocardium. The key conclusion of this study was that diastolic function is affected earlier in the disease process in the transgenic mouse model and may likely be a more sensitive indicator of a malignant FHC phenotype than hypertrophy or systolic dysfunction (Abraham et al., 2009).

Control
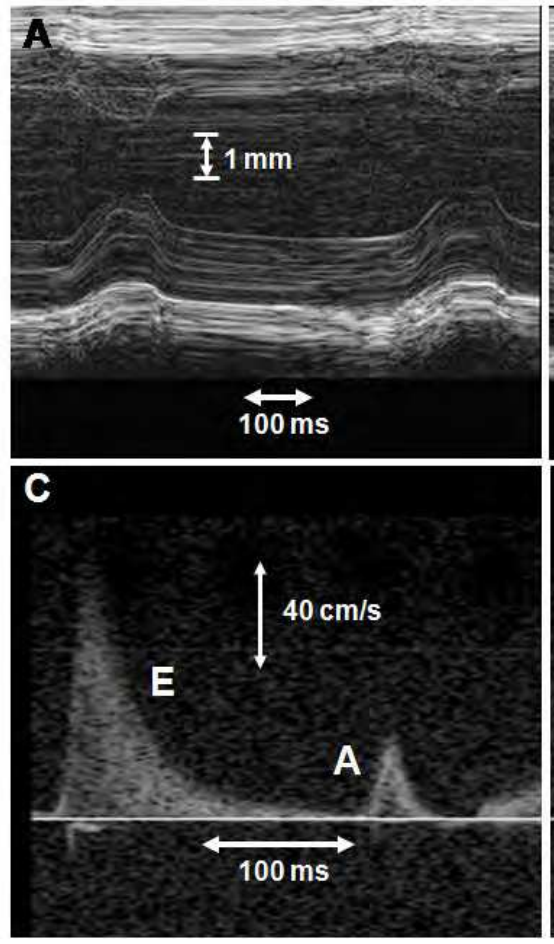

Mutant

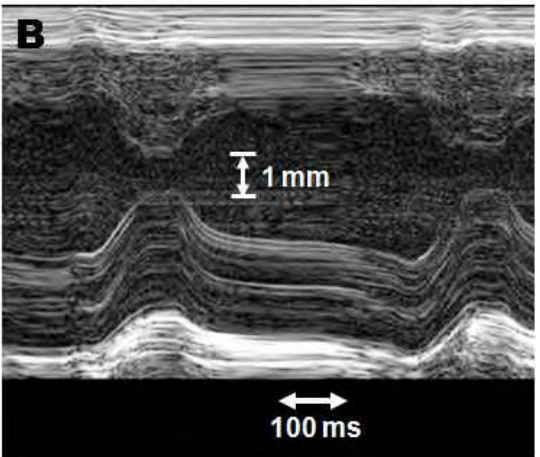

$\bar{D}$

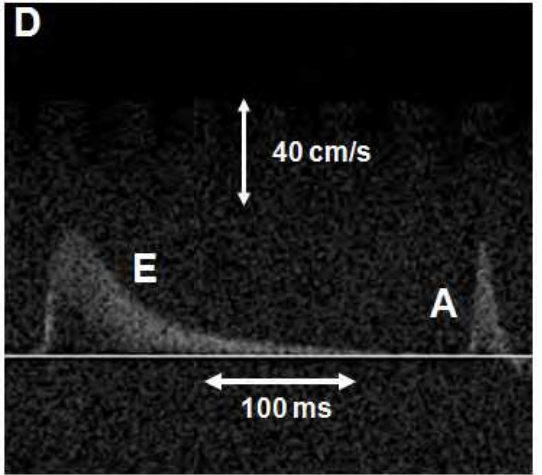

Fig. 7. Representative high resolution echocardiography B-mode images from control (A) and Tg-R58Q mice (B) show no significant difference in chamber dimensions or wall thickness. Representative pulsed Doppler tracings of the mitral valve in controls $(C)$ and TgR58Q mice (D) demonstrating reduced $\mathrm{E}$ wave velocity and longer deceleration times in the latter group (Abraham et al., 2009). 


\subsubsection{Perfused working heart model}

The hearts of transgenic mice carrying different RLC mutations were tested for the ability to perform work under conditions of physiologically relevant levels of metabolic demands and for glucose and fatty acid oxidation measured in isolated working hearts (Abraham et al., 2009; Szczesna-Cordary et al., 2007). Studies with Tg-E22K mice showed a similar energy metabolism pattern compared to control Tg-WT and NTg mouse hearts, but following 20 minutes of no flow ischemia, the E22K hearts demonstrated a slightly better recovery compared to WT hearts (Szczesna-Cordary et al., 2007). In another study with Tg-R58Q and Tg-N47K mice, it was shown that cardiac output, cardiac work and cardiac power were drastically compromised compared with controls, Tg-WT or NTg mice (Abraham et al., 2009). Additional data attained with Tg-R58Q mice also demonstrated significantly decreased cardiac efficiency in aerobically perfused R58Q hearts compared to controls and poor recovery after an acute ischemic episode confirming greatly compromised cardiac function in Tg-R58Q mice (Abraham et al., 2009). Results from these studies mirrored the severity of the human phenotypes associated with R58Q and N47K mutations, with less severe outcomes in N47K patients, while matching the malignant phenotype with multiple cases of SCD in R58Q-positive patients.

\subsubsection{Endogenous level of RLC phosphorylation}

The highly conserved Ser-15 in RLC can be reversibly phosphorylated in vivo by $\mathrm{Ca}^{2+}$ CaM-activated MLCK. Given the role that RLC phosphorylation can play in affecting thick filament structure and cardiac contractility, examining the mutation induced effect on RLC phosphorylation is important in understanding the effects of any of the FHC mutation. Mutations studied in this review can be categorized into two groups based on

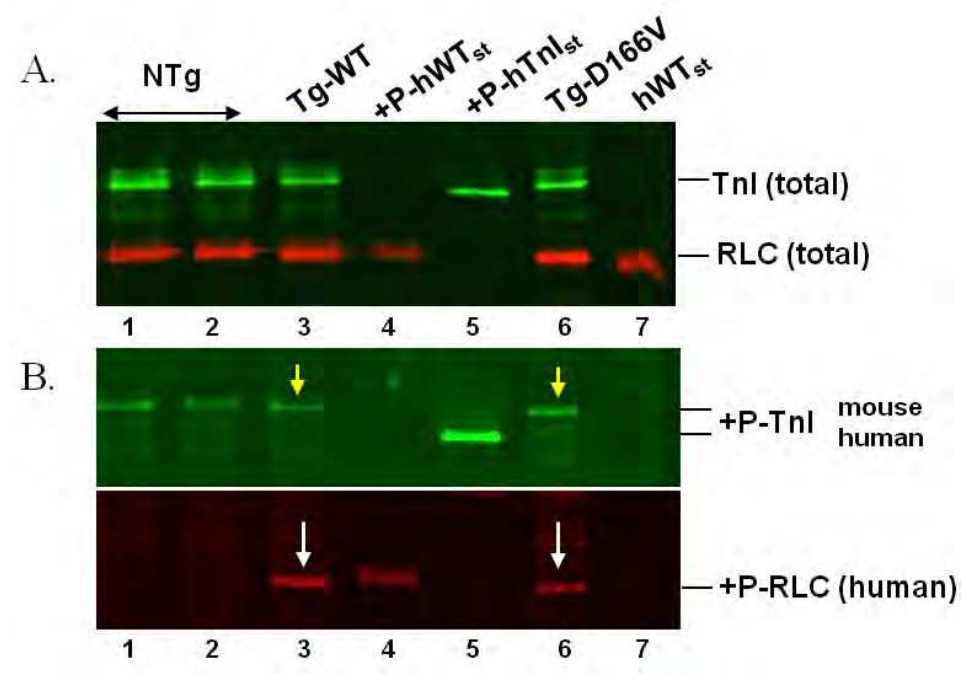

Fig. 8. The effect of the D166V mutation on the phosphorylation status of RLC and Troponin I (TnI) in transgenic mouse ventricular extracts blotted with CT-1 antibody recognizing total RLC protein and 6F9 antibody recognizing total TnI protein (A) and Mab14 MMS-418R antibody recognizing $+\mathrm{P}-\mathrm{TnI}$ (top panel) and $+\mathrm{P}$-human $\mathrm{RLC}$ antibody recognizing $+\mathrm{P}-\mathrm{RLC}$ human (Tg) (bottom panel) (B) (Kerrick et al., 2009). 
their location in the sequence and the 3D organization of RLC (Fig. 3): N47K and R58Qlocated close or within the $\mathrm{Ca}^{2+}$ binding site, and A13T, E22K and D166V- located in close proximity to the phosphorylation site (Ser-15). The status of phosphorylation was examined for transgenic mice carrying the R58Q, N47K and D166V mutations (Abraham et al., 2009; Kerrick et al., 2009; Muthu et al., 2010; Muthu et al., 2011). Mouse extracts from ventricular tissue were rapidly frozen in liquid nitrogen and analyzed by immunoblotting. The phosphorylated Tg-RLC was detected with +P-human RLC antibodies (generously provided by Dr. Neal Epstein, NIH), specific for the phosphorylated form of the ventricular RLC; followed by a secondary goat anti-rabbit antibody conjugated with the fluorescent dye, IR red 800. It was interesting to note that the mutations in RLC associated with a malignant phenotype (R58Q and D166V) displayed a reduced level of phosphorylation compared to N47K and/or WT.

The decreased level of phosphorylation coincided with those FHC mutations that are associated with a severe phenotype (Fig. 8) (Abraham et al., 2009; Kerrick et al., 2009). This suggested that phosphorylation of the regulatory light chain of myosin could have an important physiological role in the regulation of cardiac muscle contraction.

\section{Functional studies using cardiac muscle preparations}

\subsection{ATPase assays}

\subsubsection{Actin activated myosin ATPase activity}

Myosin's ability to perform mechanical work, powered by the hydrolysis of ATP, requires that the enzymatic and mechanical cycles be coupled. Both the hydrolysis of ATP and the generation of force and motion are known to be multi-step processes. The cross-bridge cycle can be broadly divided into states where myosin is strongly or weakly bound to actin. It starts with the physiologically short-lived rigor state where myosin is bound strongly to actin in the absence of ATP. If ATP or its hydrolysis products are bound (M॰ATP, $\mathrm{M} \triangleright \mathrm{ADP} \triangleright \mathrm{Pi})$, myosin shifts to the weakly bound state. Either prior to or following inorganic phosphate $(\mathrm{Pi})$ release, myosin undergoes its power stroke increasing its affinity for actin.

The actin activated myosin ATPase activity, measured as a function of actin concentration was determined for FHC-linked RLC mutants using myosin purified from the mouse hearts or RLC-depleted porcine myosin reconstituted with WT or FHC RLC mutant protein. The assay consisted of titrating myosin with increasing concentrations of skeletal muscle actin. The data were analyzed with the Michaelis-Menten equation yielding the $V_{\max }$ (maximal ATPase rate) and $K_{m}$ (apparent dissociation constant) parameters.

This assay was performed to understand the effect of the N47K and R58Q mutations on the cross bridge cycle (Greenberg et al., 2009). The maximal ATPase rates $\left(V_{\max }\right)$ for NTg $(0.43$ $\left.\mathrm{s}^{-1}\right)$ and Tg-WT $\left(0.43 \mathrm{~s}^{-1}\right)$ were seen to be similar to those of RLC carrying the N47K mutation $\left(0.43 \mathrm{~s}^{-1}\right)$. However, Tg-R58Q showed a significant increase in $V_{\max }\left(0.63 \mathrm{~s}^{-1}\right)$. On the other hand, a significant decrease in $V_{\max }$ was observed in Tg-A13T mice $\left(0.38 \mathrm{~s}^{-1}\right)$ compared to Tg-WT $\left(0.51 \mathrm{~s}^{-1}\right)$ or NTg $\left(0.63 \mathrm{~s}^{-1}\right)$ mice (unpublished data). The observed changes in the ATPase activity for the mutant RLC compared to controls suggest that the total amount of free ATP in the cell may vary affecting several ATP dependent processes in the heart and leading to the development of FHC phenotype. Moreover, as $V_{\max }$ represents the rate constant of the transition from the weakly to strongly bound myosin cross-bridges, the FHC mutations are expected to affect the kinetics of force generating myosin crossbridges and muscle contraction. 


\subsubsection{Myofibrillar ATPase activity}

To understand the effect of mutations in RLC at the myofibrillar level, assays were performed on two types of systems: porcine myofibrils reconstituted with the FHC mutant or cardiac myofibrils prepared from transgenic mice carrying the RLC mutation.

For the reconstituted myofibrillar assays, porcine cardiac myofibrils (CMF) were depleted of RLC using Triton and CDTA (Szczesna-Cordary et al., 2004a). The CDTA extraction method resulted in about $80 \%$ depletion of the endogenous RLC. These RLC depleted CMF were then reconstituted with exogenous recombinant human cardiac RLC-WT and FHC mutants (A13T, F18L, E22K, N47K and R58Q). The authors observed that myofibrils lacking the RLC demonstrated dramatic impairment of the $\mathrm{Ca}^{2+}$ regulation of ATPase activity at pCa 8 (low $\mathrm{Ca}^{2+}$ ) and 4.5 (high $\mathrm{Ca}^{2+}$ ) and also demonstrated lower $\mathrm{Ca}^{2+}$ sensitivity of ATPase. The latter was determined to be due to partial extraction of troponin $C(\operatorname{TnC})$ that occurs during RLC extraction. Reconstitution of the RLC-depleted CMF with cardiac TnC and RLC (WT or FHC mutant) recovered the $\mathrm{Ca}^{2+}$ regulation of ATPase activity, however; the maximal level of ATPase activation was slightly different for various FHC mutants with the highest level observed for R58Q-reconstituted CMF. As presented in Table 3, $\mathrm{Ca}^{2+}$ sensitivity of myofibrillar ATPase activity was significantly increased for N47K mutant, slightly increased for E22K and R58Q, slightly decreased for F18L whereas no change was monitored for A13T mutant. It is interesting to note that three of the mutants (N47K, E22K and R58Q) that increased the $\mathrm{Ca}^{2+}$ sensitivity of ATPase were seen to either decrease the affinity for $\mathrm{Ca}^{2+}$ or to inactivate the $\mathrm{Ca}^{2+}$ binding site of the human cardiac RLC (Szczesna-Cordary et al., 2004a; Szczesna et al., 2001).

Myofibrils from mouse ventricular, septal and papillary muscles of NTg, Tg-WT, Tg-E22K, Tg-R58Q and Tg-N47K mice were examined for their $\mathrm{Ca}^{2+}$ sensitivity of ATPase activity(Abraham et al., 2009; Szczesna-Cordary et al., 2005). Tg-WT and NTg myofibrils showed similar $\mathrm{pCa}_{50}$ when compared among themselves. This established that the $\mathrm{Ca}^{2+}$ sensitivity was not RLC-isoform (human versus mouse)-dependent. A statistically significant increase in the $\mathrm{Ca}^{2+}$ sensitivity of myofibrillar ATPase activity was observed between NTg or Tg-WT mice and Tg-E22K mice $\left(\Delta \mathrm{pCa}_{50} \cong 0.14\right)$ (Szczesna-Cordary et al., 2004a). Studies on myofibrils from Tg-N47K and Tg-R58Q showed a decrease in the cooperativity of the actin-myosin interaction with a much more dramatic effect exhibited by the R58Q mutation. Though these results reflect what was seen with porcine CMF reconstituted with FHC mutants, the effect seemed to be more pronounced in Tg mice. Recent studies also showed that the maximal ATPase activity in myofibrils from Tg-D166V mice were significantly lower when compared to WT. However, it is interesting to note that following phosphorylation, the low levels of ATPase activity observed in Tg-D166V was recovered to the level of Tg-WT (Muthu et al., 2011). The latter study brought to light the beneficial role that RLC phosphorylation may have on cardiac function. More details on the role of $\mathrm{Ca}^{2+}$ binding and phosphorylation of the regulatory light chain on the cross bridge cycle are discussed later in this review.

\subsection{Studies on cardiac muscle fibers}

To test the functional consequence of FHC mutations at higher levels of organization, cardiac papillary muscle fibers from transgenic mice or RLC-depleted and mutant reconstituted porcine cardiac papillary muscle fibers were used in steady-state force and ATPase measurements. 
i. Porcine cardiac papillary muscle fibers reconstituted with mutant RLC: Endogenous RLC was depleted from porcine cardiac muscle fiber preparations using CDTA and Triton (Szczesna-Cordary et al., 2004a). Depletion of endogenous RLC resulted in partial extraction of TnC (similar to that seen in porcine CMF). Therefore, TnC was added back along with the mutant RLC during reconstitution. It was observed that depletion of RLC, which was accompanied by a partial extraction of $\mathrm{TnC}$, resulted in a decrease in the maximal level of force development from $100 \%$ to $\sim 46 \%$. Reconstitution of RLC-depleted fibers with TnC and RLC-WT restored the maximal level of force to $\sim 84 \%$ (Szczesna-Cordary et al., 2004a). FHC mutants (A13T, E22K, N47K and R58Q mutants) were then tested for steady-state force development and the regulation of $\mathrm{Ca}^{2+}$ sensitivity of force. The lowest level of recovered force was observed for the E22K mutant $(66 \%)$ whereas N47K- and R58Q-reconstituted fibers demonstrated $74 \%$ and $78 \%$, respectively. Also, The E22K mutation was shown to cause a slight increase while the two $\mathrm{Ca}^{2+}$ binding site mutants, $\mathrm{N} 47 \mathrm{~K}$ and $\mathrm{R} 58 \mathrm{Q}$, showed a significantly large increase in the $\mathrm{Ca}^{2+}$ sensitivity of force development (Szczesna-Cordary et al., 2004a). Interestingly, in studies performed on skinned rabbit psoas muscle fibers reconstituted with the E22K mutation, it was observed that the tension at $\mathrm{pCa} 6.0$ and the $\mathrm{pCa} 50$ value were significantly increased compared to WT-reconstituted psoas fibers (Roopnarine, 2003).

These results were in accord with the previous studies by Levine et. al on human biopsy samples from patients carrying the E22K mutation. A leftward shift in the tension-pCa curve was observed signifying a mutation mediated increase in the $\mathrm{Ca}^{2+}$ sensitivity of force development (Levine et al., 1998). Levine's group also studied the structure of the thick filaments carrying the $\mathrm{E} 22 \mathrm{~K}$ mutation compared to normal human fibers isolated from slow skeletal muscle. The authors speculated that because the E22K mutation occurs due to the substitution of a positively charged residue for a residue that is acidic, an ordered state of myosin cross-bridges was expected in both the mutant as well as normal fibers. However, they observed a disordered state of the filaments from the mutant biopsy while the wild type filaments from the normal human sample showed an ordered relaxed state (Levine et al., 1998).

ii. Transgenic cardiac papillary muscle fibers: To avoid difficulties related to the extraction/replacement of the RLC in porcine muscle preparations, cardiac papillary muscle fibers from transgenic mice expressing RLC mutations were used. The $\mathrm{Ca}^{2+}$ sensitivity of force development was first examined in transgenic mice carrying the E22K mutation of RLC and the results compared to WT control mice (Szczesna-Cordary et al., 2005). The mutation was seen to increase the $\mathrm{Ca}^{2+}$ sensitivity of force development compared to WT. In addition, a slight gene-dose effect in the force development was observed and the glycerinated skinned muscle fibers from TgE22K L4 expressing 87\% transgene demonstrated slightly higher $\mathrm{Ca}^{2+}$ sensitivity of force than in Tg-E22K L2 expressing $67 \%$ mutant protein ( $\mathrm{pCa}_{50}=5.65$ vs. 5.62) (Szczesna-Cordary et al., 2005). The authors concluded that the E22K-mediated structural perturbations in the RLC and altered $\mathrm{Ca}^{2+}$-binding-properties were most likely responsible for the abnormal function of the mutated myocardium and initiation of hypertrophic response and FHC.

Similar force measurement studies in papillary muscle fibers from Tg-D166V mice revealed that the presence of the D166V mutation, associated with malignant clinical outcomes, caused a decrease in maximal force as well as a significant leftward shift in myofilament $\mathrm{Ca}^{2+}$ sensitivity compared to Tg-WT (Muthu et al., 2011). This report was also the first to 
demonstrate the physiological effects of RLC phosphorylation in cardiomyopathic transgenic mouse hearts. As expected, a small leftward shift in the force-pCa dependence was observed for Tg-WT papillary muscle fibers (Fig.9). In contrast, MLCK-treatment of TgD166V fibers resulted in a large decrease in myofilament $\mathrm{Ca}^{2+}$ sensitivity (Fig.9). Therefore, phosphorylation of D166V- diseased muscle reversed the increased $\mathrm{Ca}^{2+}$ sensitivity of force and brought it back to the level observed for Tg-WT.

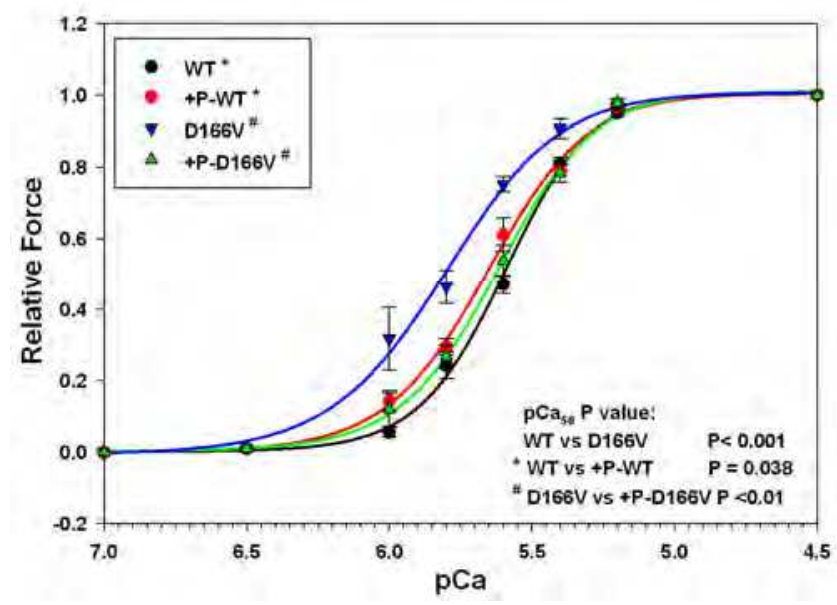

Fig. 9. Effect of RLC phosphorylation on the force-pCa relationship in skinned muscle fibers from Tg-WT mice and Tg-D166V (Muthu et al., 2011).

In addition to calcium sensitivity, the authors determined the effect of RLC phosphorylation on maximal steady-state force (Muthu et al., 2011). In contrast to Tg-WT, which displayed a phosphorylation-induced increase in force, the maximal tension in Tg-D166V papillary muscle fibers decreased upon phosphorylation. The authors concluded that phosphorylation of myosin RLC could work as a regulator of the acto-myosin interaction in both normal and cardiomyopathic hearts. A phosphorylation induced tuning of cardiac function in the diseased heart was seen to be different from the healthy heart and was anticipated to vary depending on the type and the level of cardiac insult.

Simultaneous ATPase/force- $p$ Ca relationships: Studies were designed to perform simultaneous force and ATPase measurements in freshly isolated (not glycerinated) skinned papillary muscle fibers from transgenic mice (Kerrick et al., 2009; Wang et al., 2006). ATPase activity was measured by the NADH fluorescence method (Guth \& Wojciechowski, 1986). In this method, the regeneration of ATP from ADP and PEP (phospho-enol-pyruvate) by the enzyme PK (pyruvate kinase) is coupled to the oxidation of NADH (fluorescent) to NAD (non-fluorescent) by LDH (Griffiths et al., 1980; Takashi \& Putnam, 1979). The decrease in $\mathrm{NADH}$ concentration is detected by a decrease in the fluorescence signal at $450 \mathrm{~nm}$. The slope of the linear decrease in NADH concentration is used to calculate ATPase activity. In these measurements, force was recorded simultaneously with ATPase. The concentration of $\mathrm{Ca}^{2+}$ during ATPase/force measurements was measured with Calcium Green-2 fluorescence and the data fit to the Hill equation yielding the $\mathrm{pCa}_{50}$ and Hill coefficient $\mathrm{n}_{\mathrm{H}}$ values (Kerrick et al., 2009; Wang et al., 2006). 
Skinned muscle fibers from Tg-E22K mice showed a significant (20\%) decrease in maximum ATPase and force compared to Tg-WT controls (Szczesna-Cordary et al., 2007). However, contrary to previously reported studies (Szczesna-Cordary et al., 2005) in glycerinated skinned muscle fibers, no significant difference in the $\mathrm{pCa}_{50}$ of force/ATPase-pCa relationships was observed between Tg-E22K and Tg-WT mice. Similar studies on skinned muscle fibers from Tg-D166V and Tg-R58Q mice showed that compared to Tg-WT, the mutations associated with a malignant disease phenotype (R58Q and D166V) caused large increases in the $\mathrm{Ca}^{2+}$ sensitivity of ATPase and force while those of benign phenotype (N47K) showed no changes in the force/ATPase-pCa dependence (Kerrick et al., 2009; Wang et al., 2006). Simultaneous ATPase/force-pCa measurements using freshly skinned papillary muscle fibers from Tg-D166V mice demonstrated a large increase in the $\mathrm{Ca}^{2+}$ sensitivity of force and ATPase compared to control NTg and Tg-WT mice (Kerrick et al., 2009). In addition, the maximal ATPase and force per cross-section of muscle fiber were largely decreased in the mutant Tg-D166V fibers compared to controls. The authors proceeded to calculate the rate of dissociation of the myosin heads from actin (rate of cross-bridge dissociation, " $\mathrm{g}$ ") and showed a mutation-dependent dramatic decrease in $\mathrm{g}$ at all levels of force activation (Kerrick et al., 2009). Additionally, the energy cost per cross-bridge (fiber ATPase/force) was slightly higher in Tg-D166V fibers compared to controls although the difference between Tg-D166V and Tg-WT fibers was not statistically significant (Kerrick et al., 2009). The authors speculated that a slower relaxation rate of cycling myosin crossbridges most likely triggered a series of pathological responses resulting in an abnormal regulation of cardiac muscle contraction in Tg-D166V mice.

Studies in intact papillary muscle fibers to monitor the rates and amplitudes of $\left[\mathrm{Ca}^{2+}\right]$ and force transients: In parallel to skinned fiber studies, the measurements of force and calcium transients were performed in electrically stimulated intact papillary muscle fibers (Kerrick et al., 2009; Wang et al., 2006). These experiments directly addressed potential abnormalities of the mutated myocardium of diastolic and systolic function observed in the FHC-mutated myocardium. Force and $\mathrm{Ca}^{2+}$ transients were seen to be significantly shortened in Tg-E22K intact fibers compared to Tg-WT (Szczesna-Cordary et al., 2007). The authors hypothesized that by changing the properties of the RLC Ca ${ }^{2+}-\mathrm{Mg}^{2+}$ binding site, the E22K mutation could be affecting the function of RLC as a delayed $\mathrm{Ca}^{2+}$ buffer. Consequently, a faster $\mathrm{Ca}^{2+}$ reuptake by the sarcoplasmic reticulum proteins and the shorter duration of $\left[\mathrm{Ca}^{2+}\right]$ and force transients could be expected, both indicative of enhanced muscle relaxation. In line with this explanation, the R58Q mutation, which was seen to inactivate the RLC calcium binding site for $\mathrm{Ca}^{2+}$ binding, should induce an opposite effect to E22K in intact papillary muscle fibers. This was in fact observed and significantly prolonged force and $\left[\mathrm{Ca}^{2+}\right]$ transients were monitored in Tg-R58Q papillary muscles compared to Tg-WT (Wang et al., 2006). In parallel, intact fiber studies on Tg-N47K mutation showed no change in force transients with small changes in $\left[\mathrm{Ca}^{2+}\right]$ transients (Wang et al., 2006).

In the study on the D166V mutation, the authors investigated whether the slower kinetics of force generating myosin cross-bridges, as determined in Tg-D166V skinned papillary muscle fibers (above), resulted in slower relaxation measured in intact papillary muscles from Tg-D166V mice (Kerrick et al., 2009). It was observed that the rates of force relaxation in Tg-D166V muscles were significantly slower than the rates measured in Tg-WT or NTg papillary muscle fibers. However, the prolonged force transients in Tg-D166V muscle fibers were not paralleled by delayed calcium transients and no differences were observed 
between $\left[\mathrm{Ca}^{2+}\right]$ transients of Tg-D166V versus Tg-WT or NTg intact muscle fibers (Kerrick et al., 2009). Results of this study suggested several potential D166V-mediated factors that could contribute to FHC when placed in vivo. First, a large increase in $\mathrm{Ca}^{2+}$ sensitivity could contribute to decreased ventricular filling at high heart rates when the tail end of the first $\mathrm{Ca}^{2+}$ transient begins to fuse with the second. Secondly, the slow force relaxation rate of the fibers could also start to fuse with the next contraction when heart rates are high also contributing to diastolic dysfunction. If severe enough these two factors could affect diastolic filling of the heart sufficiently to result in systolic dysfunction, i.e. decrease in stroke volume. This ultimately would cause the heart to compensate by increasing wall thickness (hypertrophy). Finally, the prediction of decreased twitch force caused by a decrease in the time constant for the rate of rise of force would also result in systolic dysfunction that could only be compensated for by increases in heart rates.

Overall, studies in skinned and intact muscle fibers from FHC transgenic animals revealed a correlation between the mutant-mediated course of the disease in humans and the extent of physiological changes observed in the studies with muscle fibers. Prolonged $\left[\mathrm{Ca}^{2+}\right]$ and force transients in intact Tg-R58Q and Tg-D166V papillary muscles as well as increased $\mathrm{Ca}^{2+}$ sensitivity of ATPase/force observed in skinned fibers correlated with a poor prognosis in R58Q and D166V mutated patients whose phenotype included SCD. Likewise, the slightly prolonged $\left[\mathrm{Ca}^{2+}\right]$ transient with no alterations in force transient, and no change in $\mathrm{Ca}^{2+}$ sensitivity of ATPase/force observed in Tg-N47K mice, correlated with the phenotype of hypertrophic cardiomyopathy described for N47K patients, including lack of SCD.

\section{Studies with single molecules}

\subsection{In vitro motility assays}

In vitro motility assays were utilized to examine the effects of FHC RLC mutations on the biochemical and mechanical properties of myosin isolated from the hearts of transgenic mice or reconstituted with the recombinant human cardiac WT or FHC mutant. In the study by Greenberg et al., myosin was purified from Tg-N47K and Tg-R58Q mouse hearts and used in in vitro motility assays with Tg-WT myosin as a control (Greenberg et al., 2009). Unregulated motility assays were used to determine whether the mutations caused any changes in the duty cycle and/or actin filament sliding velocity. The principle behind this assay was that the actin filament moves at its maximal velocity when incubated with enough myosin to ensure that at least one myosin head is interacting with the actin filament at all times. Therefore, the amount of myosin required to achieve maximal velocity would give a qualitative measurement of the duty cycle. The authors observed a significant increase in velocity caused by the R58Q mutation while no major change in actin sliding velocity was observed for Tg-N47K myosin compared to Tg-WT (Greenberg et al., 2009).

Additionally, the isometric force of the mutant myosins was studied using a frictional loading assay (Greenberg et al., 2009). A low affinity actin binding protein, a-actinin, was introduced in the assay and the concentration of a-actinin needed to stop the filament motility was used as a measurement of myosin isometric force. Tg-N47K myosin showed a dramatic reduction in isometric force while a less pronounced decrease in force was seen for Tg-R58Q compared to Tg-WT myosins. The authors also determined the effect of RLC mutation on the velocity-pCa dependence using actin complexed with the regulatory proteins, troponin and tropomyosin (Greenberg et al., 2009). While Tg-R58Q myosin showed a significant leftward shift in the calcium sensitivity of velocity, Tg-N47K and Tg- 
WT myosins showed no difference in the velocity-pCa curve. This result was consistent with the earlier (Wang et al., 2006) and more recent (Mettikolla et al., 2011) fiber studies using papillary muscles from these mice, where a significant increase in the $\mathrm{Ca}^{2+}$ sensitivity of force was observed for Tg-R58Q mice. Though both Tg-R58Q and Tg-N47K myosins displayed a reduction in isometric force, the authors concluded that the more extreme phenotype for R58Q could stem from an increase in myosin ATPase activity (discussed above in "Actin activated myosin ATPase assays") (Greenberg et al., 2009). On the other hand, study results with myosin isolated from transgenic E22K mice showed no effect of the mutation on actin sliding velocity or the velocity-pCa dependence (Szczesna-Cordary et al., 2007).

The effect of R58Q and N47K mutations was further tested using porcine myosin depleted of endogenous RLC and reconstituted with the mutant (R58Q or N47K) RLC proteins (Greenberg et al., 2010). The authors examined the effects of these mutations on the mechanical properties of myosin under both unloaded and loaded conditions. They found that, whereas the mutant myosins were indistinguishable from the controls (WT or native myosin) under unloaded conditions, both R58Q- and N47K-exchanged myosins showed reductions in force and power output compared with WT or native myosin. They also showed that the changes in loaded kinetics resulted from mutation-induced loss of myosin strain sensitivity of ADP affinity (Greenberg et al., 2010). The authors concluded that the R58Q and N47K mutations alter the mechanical properties of the myosin neck region, leading to altered load dependent kinetics that may explain the observed mutant-induced FHC phenotypes (Greenberg et al., 2010).

\subsection{Single molecule detection (SMD)}

The advances in single molecule detection (SMD) by fluorescence techniques were employed to study some of the earlier discussed FHC-linked RLC mutations. The advantage of SMD includes studying the motion of a small population of myosin cross bridges while working in their native environment of the sarcomere. Another advantage of this approach is the ability to unambiguously determine the behavior (kinetics, orientation, etc.) of the normal versus mutated muscle by observing a few molecules (myosin cross-bridges). Since humans are heterozygous for FHC mutations, the distribution of the healthy and diseased molecules is random and any collection containing more than a few molecules carries a high probability of containing a mixture of healthy and diseased moieties. It is therefore essential to use a technique such as SMD which is capable of monitoring properties of single molecules without averaging over ensembles of molecules with different properties.

The E22K substitution was the first FHC-associated mutation in RLC studied by SMD (Dumka et al., 2006). Mechanical events were measured by monitoring the anisotropy of actin labeled with rhodamine phalloidin. The measurements were done on a small population of cross bridges in contracting $\mathrm{Tg}-\mathrm{WT}$ and $\mathrm{Tg}-\mathrm{E} 22 \mathrm{~K}$ cardiac myofibrils. The results showed that the mutation did not significantly affect the time of cross-bridge dissociation and had no major effect on the mechanical performance of the cross bridges. Another mutation that was studied using SMD was the D166V mutation associated with a malignant FHC phenotype (Borejdo et al., 2010; Mettikolla et al., 2009; Muthu et al., 2010). In one experiment, myofibrils from Tg-D166V mice were labeled with Alexa 488-phalloidin and the measurements of the fluorescence lifetime (average rate of decay of a fluorescent species from its excited state) of the actin attached fluorophores were performed. No 
differences between lifetimes of Tg-WT and Tg-D166V muscle were observed (Mettikolla et al., 2009).

In addition to fluorescence lifetime, a meaningful indicator of the state of muscle that can be studied with SMD is the cross-bridge duty cycle (Mettikolla et al., 2009; Muthu et al., 2010). It was assumed that a cross-bridge is in its strongly attached to actin state for a period of time $t_{\mathrm{s}}$, while it remains in a dissociated or a weakly attached state for a period of time, $t_{\mathrm{d}}$. The ratio $\Psi=t_{\mathrm{s}} /\left(t_{\mathrm{d}}+t_{\mathrm{s}}\right)$, was defined as the duty cycle. To measure $\Psi$, one can follow the changes in the environment of a cross-bridge while it undergoes a cycle of association and dissociation from actin. In the study by Muthu et al. the authors derived the myosin crossbridge kinetic rates by tracking the orientation of a fluorescently labeled single actin molecule (Muthu et al., 2010). Orientation (measured by polarized fluorescence) oscillated between two states, corresponding to the actin-bound $\left(t_{\mathrm{s}}\right)$ and actin-free $\left(t_{\mathrm{d}}\right)$ states of the myosin cross-bridge. The rate of cross-bridge attachment during isometric contraction decreased from $3 \mathrm{~s}^{-1}$ in myofibrils from Tg-WT to $1.4 \mathrm{~s}^{-1}$ in myofibrils from Tg-D166V. The rate of detachment decreased from $1.3 \mathrm{~s}^{-1}$ (Tg-WT) to $1.2 \mathrm{~s}^{-1}$ (Tg-D166V). In addition, the average value of the duty cycle in isometrically contracting myofibrils from $\mathrm{Tg}-\mathrm{WT}$ and $\mathrm{Tg}$ D166V mice was 30\% and 50\%, respectively (Muthu et al., 2010). The authors hypothesized that the slower kinetics of Tg-D166V myosin cross-bridges could be the result of a mutationmediated decrease in endogenous phosphorylation of myosin RLC, as was observed in the hearts of Tg-D166V mice (Kerrick et al., 2009). Indeed, the authors showed that the level of RLC phosphorylation was largely decreased in Tg-D166V myofibrils compared to Tg-WT (Muthu et al., 2010). They concluded that the D166V-induced change in the cross-bridge kinetics could further lead to abnormalities in diastolic and/or systolic function that in the long term would result in a compensatory hypertrophy and sudden cardiac death, as observed in patients harboring the D166V mutation in RLC.

The SMD technique was further refined in the study by Borejdo et al. (Borejdo et al., 2010). The authors analyzed the probability distribution of polarized intensity fluctuations and measured fluctuations by recording the parallel and perpendicular components of fluorescent light emitted by an actin-bound fluorophore (Borejdo et al., 2010). The histograms of fluctuations of fluorescent actin molecules in Tg-WT hearts in rigor were represented by perfect Gaussian curves. In contrast, histograms of contracting heart muscle were peaked and asymmetric, suggesting that contraction in the heart driven by the interaction of myosin cross-bridges with actin occurred in at least two steps (Borejdo et al., 2010). Importantly, there were statistically significant differences between the histograms of contracting FHC-linked R58Q and D166V cardiac muscle preparations versus corresponding contracting WT hearts. On the basis of these results, the authors suggested a simple new method of distinguishing between healthy and FHC R58Q and D166V hearts by analyzing the probability distribution of polarized fluorescence intensity fluctuations of sparsely labeled actin molecules (Borejdo et al., 2010).

Further studies using SMD were performed on cardiac myofibrils from Tg-R58Q mice (Mettikolla et al., 2011). The results showed that the R58Q mutation resulted in a decrease in the rate of cross-bridge binding to actin, dissociation from actin and a decreased rate at which the cross-bridge undergoes the power stroke (Mettikolla et al., 2011). The authors hypothesized that slower R58Q cross-bridge kinetics were most likely responsible for the lower force measured in Tg-R58Q skinned muscle fibers. The combined data on the R58Q mutation led the authors to conclude that the R58Q hearts may be subject to inefficient energy utilization and compromised heart performance. 


\section{Concluding remarks and future directions}

With the advent of molecular biology and the ability to clone, express and purify myosin RLC and the FHC-linked mutations, it has been possible to begin to reconstruct muscle with various RLC mutants to learn about their function in increasingly more complex systems. The advance of transgenesis has catapulted the researchers to a new era of research where the function of FHC-linked RLC mutations could be studied in vivo in transgenic mouse hearts. Using various innovative approaches applied at the single molecule, skinned fiber, and intact muscle levels, it has been possible to begin to understand the effect of FHC mutations on cardiac function. The presented results indicate that RLC phosphorylation and $\mathrm{Ca}^{2+}$ binding to the RLC EF-hand calcium binding site may play important roles not only in the physiological performance of the heart, but also in muscle contraction of the diseased heart. The MLCK-dependent phosphorylation of RLC was shown to be critical to maintain normal cardiac function and was suggested to be especially important in the adaptive responses of the heart to pathophysiological injury. Unraveling the molecular basis of RLCmediated cardiac dysfunction can ultimately open new possibilities for an effective treatment(s) and efforts should be directed towards developing phosphorylation-mediated rescue strategies. Collectively, the results presented in this review provided insight into the mechanisms underlying the development of FHC disease caused by the mutations in the cardiac RLC. Future investigations should be focused on the preventive treatments to alleviate or reverse the detrimental effects of all identified RLC mutations.

\section{Acknowledgments}

This work was supported by grants from the National Institutes of Health (HL071778 and HL090786) to Danuta Szczesna-Cordary and the American Heart Association (10POST3420009) to Priya Muthu.

\section{References}

Abraham, T.P.; Jones, M.; Kazmierczak, K.; Liang, H.-Y.; Pinheiro, A.C.; Wagg, C.S.; Lopaschuk, G.D. \& Szczesna-Cordary, D. (2009). Diastolic dysfunction in familial hypertrophic cardiomyopathy transgenic model mice. Cardiovasc Res. 82:84-92.

Alcalai, R.; Seidman, J.G. \& Seidman, C.E. (2008). Genetic basis of hypertrophic cardiomyopathy: from bench to the clinics. J Cardiovasc Electrophysiol. 19:104-10.

Andersen, P.S.; Havndrup, O.; Bundgaard, H.; Moolman-Smook, J.C.; Larsen, L.A.; Mogensen, J.; Brink, P.A.; Borglum, A.D.; Corfield, V.A.; Kjeldsen, K.; Vuust, J. \& Christiansen, M. (2001). Myosin light chain mutations in familial hypertrophic cardiomyopathy: phenotypic presentation and frequency in Danish and South African populations. J Med Genet. 38:E43.

Binder, W.D.; Fifer, M.A.; King, M.E. \& Stone, J.R. (2005). Case records of the Massachusetts General Hospital. Case 26-2005. A 48-year-old man with sudden loss of consciousness while jogging. $N$ Engl J Med. 353:824-32.

Borejdo, J.; Szczesna-Cordary, D.; Muthu, P. \& Calander, N. (2010). Familial hypertrophic cardiomyopathy can be characterized by a specific pattern of orientation fluctuations of actin molecules. Biochemistry. 49:5269-77. 
Chen, Y.H. \& Yang, J.T. (1971). A new approach to the calculation of secondary structures of globular proteins by optical rotatory dispersion and circular dichroism. Biochem Biophys Res Commun. 44:1285-91.

Colson, B.A.; Locher, M.R.; Bekyarova, T.; Patel, J.R.; Fitzsimons, D.P.; Irving, T.C. \& Moss, R.L. (2010). Differential roles of regulatory light chain and myosin binding proteinC phosphorylations in the modulation of cardiac force development. J Physiol. 588:981-93.

Ding, P.; Huang, J.; Battiprolu, P.K.; Hill, J.A.; Kamm, K.E. \& Stull, J.T. (2010). Cardiac myosin light chain kinase is necessary for myosin regulatory light chain phosphorylation and cardiac performance in vivo. J Biol Chem. 285:40819-29.

Dumka, D.; Talent, J.; Akopova, I.; Guzman, G.; Szczesna-Cordary, D. \& Borejdo, J. (2006). E22K mutation of RLC that causes familial hypertrophic cardiomyopathy in heterozygous mouse myocardium: effect on cross-bridge kinetics. Am J Physiol Heart Circ Physiol. 291:H2098-2106.

Flavigny, J.; Richard, P.; Isnard, R.; Carrier, L.; Charron, P.; Bonne, G.; Forissier, J.F.; Desnos, M.; Dubourg, O.; Komajda, M.; Schwartz, K. \& Hainque, B. (1998). Identification of two novel mutations in the ventricular regulatory myosin light chain gene (MYL2) associated with familial and classical forms of hypertrophic cardiomyopathy. J Mol Med. 76:208-14.

Geeves, M.A. \& Holmes, K.C. (2005). The molecular mechanism of muscle contraction. Adv Protein Chem. 71:161-93.

Greenberg, M.J.; Kazmierczak, K.; Szczesna-Cordary, D. \& Moore, J.R. (2010). Cardiomyopathy-linked myosin regulatory light chain mutations disrupt myosin strain-dependent biochemistry. Proc Natl Acad Sci U S A. 107:17403-8.

Greenberg, M.J.; Watt, J.D.; Jones, M.; Kazmierczak, K.; Szczesna-Cordary, D. \& Moore, J.R. (2009). Regulatory light chain mutations associated with cardiomyopathy affect myosin mechanics and kinetics. J Mol Cell Cardiol. 46:108-115.

Griffiths, P.J.; Guth, K.; Kuhn, H.J. \& Ruegg, J.C. (1980). ATPase activity in rapidly activated skinned muscle fibres. Pflugers Arch. 387:167-73.

Guth, K. \& Wojciechowski, R. (1986). Perfusion cuvette for the simultaneous measurement of mechanical, optical and energetic parameters of skinned muscle fibres. Pflugers Arch. 407:552-7.

Hartshorne, D.J. \& Mrwa, U. (1982). Regulation of smooth muscle actomyosin. Blood Vessels. 19:1-18.

Houdusse, A. \& Cohen, C. (1996). Structure of the regulatory domain of scallop myosin at 2 A resolution: implications for regulation. Structure. 4:21-32.

Hougs, L.; Havndrup, O.; Bundgaard, H.; Kober, L.; Vuust, J.; Larsen, L.A.; Christiansen, M. \& Andersen, P.S. (2005). One third of Danish hypertrophic cardiomyopathy patients have mutations in MYH7 rod region. Eur J Hum Genet. . 13:161-165.

Howard, J. \& Spudich, J.A. (1996). Is the lever arm of myosin a molecular elastic element? Proc Natl Acad Sci U S A. 93:4462-4.

Huang, W.; Muthu, P.; Kazmierczak, K. \& Szczesna-Cordary, D. (2011). FHC-Linked Myosin Regulatory Light Chain Mutations A13T and K104E Do Not Generate Major Structural Changes Sufficient to Affect Binding of Myosin to Actin. Biophysical journal. 100:110a-111a.

Kabaeva, Z.T.; Perrot, A.; Wolter, B.; Dietz, R.; Cardim, N.; Correia, J.M.; Schulte, H.D.; Aldashev, A.A.; Mirrakhimov, M.M. \& Osterziel, K.J. (2002). Systematic analysis of 
the regulatory and essential myosin light chain genes: genetic variants and mutations in hypertrophic cardiomyopathy. Eur J Hum Genet. 10:741-8.

Kamm, K.E. \& Stull, J.T. (2011). Signaling to Myosin Regulatory Light Chain in Sarcomeres. Journal of Biological Chemistry. 286:9941-9947.

Kerrick, W.G.L.; Kazmierczak, K.; Xu, Y.; Wang, Y. \& Szczesna-Cordary, D. (2009). Malignant familial hypertrophic cardiomyopathy D166V mutation in the ventricular myosin regulatory light chain causes profound effects in skinned and intact papillary muscle fibers from transgenic mice. FASEB J. 23:855-865.

Levine, R.J.; Yang, Z.; Epstein, N.D.; Fananapazir, L.; Stull, J.T. \& Sweeney, H.L. (1998). Structural and functional responses of mammalian thick filaments to alterations in myosin regulatory light chains. J Struct Biol. 122:149-61.

Lowey, S.; Waller, G.S. \& Trybus, K.M. (1993). Skeletal muscle myosin light chains are essential for physiological speeds of shortening. Nature. 365:454-6.

Mettikolla, P.; Calander, N.; Luchowski, R.; Gryczynski, I.; Gryczynski, Z.; Zhao, J.; Szczesna-Cordary, D. \& Borejdo, J. (2011). Cross-bridge kinetics in myofibrils containing familial hypertrophic cardiomyopathy R58Q mutation in the regulatory light chain of myosin. J Theor Biol. 284:71-81.

Mettikolla, P.; Luchowski, R.; Gryczynski, I.; Gryczynski, Z.; Szczesna-Cordary, D. \& Borejdo, J. (2009). Fluorescence Lifetime of Actin in the Familial Hypertrophic Cardiomyopathy Transgenic Heart. Biochemistry. 48:1264-1271.

Morano, I. (1999). Tuning the human heart molecular motors by myosin light chains. J Mol Med. 77:544-55.

Morner, S.; Richard, P.; Kazzam, E.; Hellman, U.; Hainque, B.; Schwartz, K. \& Waldenstrom, A. (2003). Identification of the genotypes causing hypertrophic cardiomyopathy in northern Sweden. J Mol Cell Card. 35:841-849.

Muthu, P.; Kazmierczak, K.; Jones, M. \& Szczesna-Cordary, D. (2011). The effect of myosin RLC phosphorylation in normal and cardiomyopathic mouse hearts. J Cell Mol Med.

Muthu, P.; Mettikolla, P.; Calander, N.; Luchowski, R.; Gryczynski, I.; Gryczynski, Z.; Szczesna-Cordary, D. \& Borejdo, J. (2010). Single molecule kinetics in the familial hypertrophic cardiomyopathy D166V mutant mouse heart. J Mol Cell Cardiol. 48:989-998.

Pant, K.; Watt, J.; Greenberg, M.; Jones, M.; Szczesna-Cordary, D. \& Moore, J.R. (2009). Removal of the cardiac myosin regulatory light chain increases isometric force production. FASEB J. 23:3571-3580.

Poetter, K.; Jiang, H.; Hassanzadeh, S.; Master, S.R.; Chang, A.; Dalakas, M.C.; Rayment, I.; Sellers, J.R.; Fananapazir, L. \& Epstein, N.D. (1996). Mutations in either the essential or regulatory light chains of myosin are associated with a rare myopathy in human heart and skeletal muscle. Nat Genet. 13:63-9.

Rayment, I.; Rypniewski, W.R.; Schmidt-Base, K.; Smith, R.; Tomchick, D.R.; Benning, M.M.; Winkelmann, D.A.; Wesenberg, G. \& Holden, H.M. (1993). Three-dimensional structure of myosin subfragment-1: a molecular motor. Science. 261:50-8.

Richard, P.; Charron, P.; Carrier, L.; Ledeuil, C.; Cheav, T.; Pichereau, C.; Benaiche, A.; Isnard, R.; Dubourg, O.; Burban, M.; Gueffet, J.-P.; Millaire, A.; Desnos, M.; Schwartz, K.; Hainque, B.; Komajda, M. \& for the EUROGENE Heart Failure Project (2003). Hypertrophic cardiomyopathy: Distribution of disease genes, spectrum of mutations, and implications for a molecular diagnosis strategy. Circulation. 107:2227-2232. 
Richard, P.; Charron, P.; Carrier, L.; Ledeuil, C.; Cheav, T.; Pichereau, C.; Benaiche, A.; Isnard, R.; Dubourg, O.; Burban, M.; Gueffet, J.-P.; Millaire, A.; Desnos, M.; Schwartz, K.; Hainque, B.; Komajda, M. \& for the EUROGENE Heart Failure Project (2004). Correction to: "Hypertrophic cardiomyopathy: distribution of disease genes, spectrum of mutations, and implications for a molecular diagnosis strategy". Circulation. 109:3258.

Robertson, S.P.; Johnson, J.D. \& Potter, J.D. (1981). The time-course of $\mathrm{Ca}^{2+}$ exchange with calmodulin, troponin, parvalbumin, and myosin in response to transient increases in Ca2+. Biophys J. 34:559-69.

Roopnarine, O. (2003). Mechanical Defects of Muscle Fibers with Myosin Light Chain Mutants that Cause Cardiomyopathy. Biophys. J. 84:2440-2449.

Sanbe, A.; Nelson, D.; Gulick, J.; Setser, E.; Osinska, H.; Wang, X.; Hewett, T.E.; Klevitsky, R.; Hayes, E.; Warshaw, D.M. \& Robbins, J. (2000). In vivo analysis of an essential myosin light chain mutation linked to familial hypertrophic cardiomyopathy. Circ Res. 87:296-302.

Small, J.V. \& Sobieszek, A. (1977). Ca-regulation of mammalian smooth muscle actomyosin via a kinase-phosphatase-dependent phosphorylation and dephosphorylation of the 20 000-Mr light chain of myosin. Eur J Biochem. 76:521-30.

Sobieszek, A. (1977). Ca-linked phosphorylation of a light chain of vertebrate smoothmuscle myosin. Eur J Biochem. 73:477-83.

Szczesna-Cordary, D.; Guzman, G.; Ng, S.S. \& Zhao, J. (2004a). Familial hypertrophic cardiomyopathy-linked alterations in $\mathrm{Ca}^{2+}$ binding of human cardiac myosin regulatory light chain affect cardiac muscle contraction. J Biol Chem. 279:3535-42.

Szczesna-Cordary, D.; Guzman, G.; Zhao, J.; Hernandez, O.; Wei, J. \& Diaz-Perez, Z. (2005). The E22K mutation of myosin RLC that causes familial hypertrophic cardiomyopathy increases calcium sensitivity of force and ATPase in transgenic mice. J Cell Sci. 118:3675-83.

Szczesna-Cordary, D.; Jones, M. \& Guzman, G. (2004b). Interaction of Myosin Regulatory Light Chain Mutants Implicated in Familial Hypertrophic Cardiomyopathy with IQ-Myosin Heavy Chain Peptides. Biophys J. 86:393a.

Szczesna-Cordary, D.; Jones, M.; Moore, J.R.; Watt, J.; Kerrick, W.G.L.; Xu, Y.; Wang, Y.; Wagg, C. \& Lopaschuk, G.D. (2007). Myosin regulatory light chain E22K mutation results in decreased cardiac intracellular calcium and force transients. FASEB J. 21:3974-3985.

Szczesna, D. (2003). Regulatory light chains of striated muscle myosin. Structure, function and malfunction. Curr Drug Targets Cardiovasc Haematol Disord. 3:187-97.

Szczesna, D.; Ghosh, D.; Li, Q.; Gomes, A.V.; Guzman, G.; Arana, C.; Zhi, G.; Stull, J.T. \& Potter, J.D. (2001). Familial hypertrophic cardiomyopathy mutations in the regulatory light chains of myosin affect their structure, $\mathrm{Ca}^{2+}$ binding, and phosphorylation. J Biol Chem. 276:7086-92.

Takashi, R. \& Putnam, S. (1979). A fluorimetric method for continuously assaying ATPase: application to small specimens of glycerol-extracted muscle fibers. Anal Biochem. 92:375-82.

Wang, Y.; Xu, Y.; Kerrick, W.G.L.; Wang, Y.; Guzman, G.; Diaz-Perez, Z. \& SzczesnaCordary, D. (2006). Prolonged $\mathrm{Ca}^{2+}$ and force transients in myosin RLC transgenic mouse fibers expressing malignant and benign FHC mutations. J Mol Biol. 361:286299. 


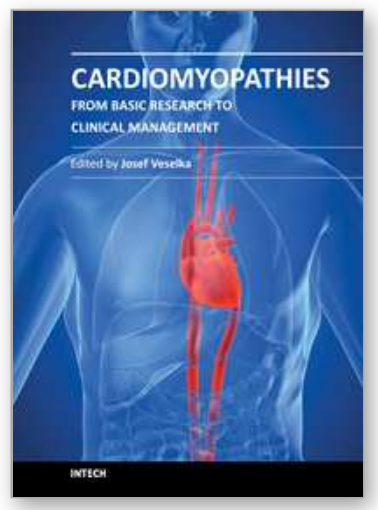

\author{
Cardiomyopathies - From Basic Research to Clinical Management \\ Edited by Prof. Josef Veselka
}

ISBN 978-953-307-834-2

Hard cover, 800 pages

Publisher InTech

Published online 15, February, 2012

Published in print edition February, 2012

Cardiomyopathy means "heart (cardio) muscle (myo) disease (pathy)". Currently, cardiomyopathies are defined as myocardial disorders in which the heart muscle is structurally and/or functionally abnormal in the absence of a coronary artery disease, hypertension, valvular heart disease or congenital heart disease sufficient to cause the observed myocardial abnormalities. This book provides a comprehensive, state-of-theart review of the current knowledge of cardiomyopathies. Instead of following the classic interdisciplinary division, the entire cardiovascular system is presented as a functional unity, and the contributors explore pathophysiological mechanisms from different perspectives, including genetics, molecular biology, electrophysiology, invasive and non-invasive cardiology, imaging methods and surgery. In order to provide a balanced medical view, this book was edited by a clinical cardiologist.

\title{
How to reference
}

In order to correctly reference this scholarly work, feel free to copy and paste the following:

Priya Muthu, Wenrui Huang, Katarzyna Kazmierczak and Danuta Szczesna-Cordary (2012). Functional Consequences of Mutations in the Myosin Regulatory Light Chain Associated with Hypertrophic Cardiomyopathy, Cardiomyopathies - From Basic Research to Clinical Management, Prof. Josef Veselka (Ed.), ISBN: 978-953-307-834-2, InTech, Available from: http://www.intechopen.com/books/cardiomyopathies-frombasic-research-to-clinical-management/functional-consequences-of-mutations-in-the-myosin-regulatory-lightchain-associated-with-hypertroph

\section{INTECH}

open science | open minds

\section{InTech Europe}

University Campus STeP Ri

Slavka Krautzeka 83/A

51000 Rijeka, Croatia

Phone: +385 (51) 770447

Fax: +385 (51) 686166

www.intechopen.com

\section{InTech China}

Unit 405, Office Block, Hotel Equatorial Shanghai

No.65, Yan An Road (West), Shanghai, 200040, China

中国上海市延安西路65号上海国际贵都大饭店办公楼405单元

Phone: +86-21-62489820

Fax: $+86-21-62489821$ 
(C) 2012 The Author(s). Licensee IntechOpen. This is an open access article distributed under the terms of the Creative Commons Attribution 3.0 License, which permits unrestricted use, distribution, and reproduction in any medium, provided the original work is properly cited. 